\title{
The effect of variant transformations in the fusion zones of gas metal arc welds
}

\begin{abstract}
The macro- and microtextures of gas metal arc (GMA / GMAW) welds fabricated using both conventional ferritic and low transformation (LTT) filler metals were examined. Both welds were largely composed of acicular ferrite. The weld textures were found to be distinct, which is observed to be due to variant selection during the austenite-to-ferrite transformation. In situ EBSD performed on thermal cycling of the LTT fusion zone into the austenite phase field confirmed that these transformations satisfy the expected crystallographic relationships. Implications for welding consumable design and finite element process modelling are drawn.
\end{abstract} Keywords: Texture analysis; Displacive transformation; Variant selection; Gas Metal Arc Weld.

\section{Introduction}

The thermal strains that arise during welding give rise to residual stresses and distortion in welded joints that are problematic, both in initial fabrication of a satisfactory structure and its subsequent strength, fatigue and stress-corrosion cracking performance. ${ }^{1,2}$ However, in the majority of welds a filler metal is added and therefore the possibility exists to select a filler material with the aim of improving the performance of the welded joint. Over recent years, here has been much interest in using filler metals during the welding of steels that exploit the austenite-to-ferrite $(\gamma \rightarrow \alpha)$ transformation strains to absorb some of the thermal strains from welding, mitigating the residual stress and distortion. ${ }^{3-9}$ It has been shown that weld fabrication using, for example, filler metal wires with a lowered $\gamma \rightarrow \alpha$ transformation temperature (so-called low transformation temperature or LTT wires) can result in lowered residual stresses and distortion..$^{8,10-12}$ 
Where the transformation is entirely reconstructive, one might initially believe that the transformation strain will simply be due to the volume change between the two unit cells. However, for a fully displacive transformation, one must consider if the applied stress state can bias which orientations of the product phase form from the parent - in the case of the $\gamma \rightarrow \alpha$ transformation 24 crystallographic variants of the bcc/bct ferritic (bainite or martensite) phase can form from the austenite.

However, even for fully reconstructive transformations some 'memory' is commonly observed in the product phase textures. For example, in $\mathrm{Zr}$ and $\mathrm{Ti}$ it is now commonly accepted that the simultaneous satisfaction of the orientation relationship (OR) at the parent phase grain boundary by the product phase can result in a memory effect. ${ }^{13-15}$ Such an effect has also been observed in the macroscopic textures observed using in situ synchrotron diffraction in a interstitial-free (IF) steel. ${ }^{16}$

For displacive transformations the OR between the two phases is complicated by the possibility to minimise the strain at the interface plane by slight rotations from the ideal OR, as shown by Mackenzie and Bowles ${ }^{17,18}$ and Wechsler et al. ${ }^{19}$ in the phenomenological theory of martensite crystallography. The overall transformation elastic strain tensor can be calculated and compare to the applied stress, resulting in a calculation of which variants are favoured by the applied stress state..$^{20-23}$ Bhadeshia $^{10}$ showed that the volume change due to the transformation in bainite is much smaller than the shear component. Babu and Bhadeshia $^{24}$ studied the effect of applied stress on the formation of acicular ferrite. In series of heat treatment experiments and subsequent microstructural observations they revealed at least six crystallographic variants form where no stress is applied and that many fewer are observed when the transformation occurs under an applied elastic load. Of course, plastic strains can also have an effect by favouring variants that grow across slip planes and by the hindering of plate growth by plastic damage. ${ }^{25-27}$ 
Hase $e t a l .{ }^{28}$ examined the influence of stress on the transformation kinetics of upper bainite. It was found that compressive stresses of 4-200 MPa strongly favoured the growth of compliant variants, potentially even leading to large regions of bainite in identical orientations. In addition, they demonstrated that the stress increases the bainite start temperature and accelerates the kinetics of the transformation.

In the present paper, we demonstrate that these effects do operate in LTT filler metal, but that the effect is not discernible in conventional weld filler $(\mathrm{CW})$, and so that these transformations are relevant to weld models for the mitigation of residual stress and distortion using LTT fillers. The macro- and micro- textures have been observed in LTT and CW welds and fusion zone material from these welds is then characterised using in situ electron backscatter diffraction (EBSD) during thermal cycling.

\section{Experimental Description}

Weld samples were fabricated using manual gas metal arc welding (GMAW) procedure. ${ }^{29-}$

${ }^{31}$ Two high strength low alloy steel plates of dimensions $500 \mathrm{~mm}$ long, $250 \mathrm{~mm}$ wide and 4 $\mathrm{mm}$ in thickness were single pass butt welded. A conventional weld wire $(\mathrm{CW})$ with high transformation temperature i.e. $560{ }^{\circ} \mathrm{C}$, and a consumable with a low transformation temperature (LTT) i.e. $420{ }^{\circ} \mathrm{C}$ were used in the fabrication of the welds. ${ }^{32}$ Plates were held apart by series of three tack welds $25 \mathrm{~mm}$ long which were located in the plate centre and at the both ends. Ceramic backing tiles were used to contain the weld pool. During welding, plates were unrestrained and rested on wooden pallets. The chemical compositions of the plates and the weld consumables are shown in Table 1. The welding was performed using parameters shown in Table 2. Residual stresses in the welded plates were measured employing the neutron diffraction technique and were reported in. ${ }^{29,31,32}$ The results indicates, remarkably different residual stress pattern in longitudinal direction. While in the fusion zone 
and its vicinity of plates welded with $\mathrm{CW}$ wire, tensile stresses of magnitude $440 \mathrm{MPa}$ were developed, in the LTT filler compressive stresses of around $100 \mathrm{MPa}$ are present. Macrograph from plate welded with conventional weld wire, Figure 1, shows width of fusion zone and heat affected zone which is approximately $10 \mathrm{~mm}$ and $20 \mathrm{~mm}$, respectively. The shape of the weld on the lower side replicates the contours of ceramic backing tiles used during the welding. It is also obvious that, the weld does not fill the gap fully on the upper side.

All of the microstructural observations including conventional transmission electron microscopy (TEM), scanning electron microscopy (SEM) and electron backscattering diffraction (EBSD) were carried out in longitudinal direction of specimens extracted from the butt welded plate (i.e. in weld cross-section). For TEM examinations, specimens were cut about $1 \mathrm{~mm}$ in thickness. The specimens were ground on $\mathrm{SiC}$ paper up to 1200 grade down to a thickness of $200 \mu \mathrm{m}$. The final foil specimens for TEM were prepared from punched $3 \mathrm{~mm}$ discs, after fine grinding on $\mathrm{SiC}$ paper up to 4000 grade down to a thickness of about $50 \mu \mathrm{m}$. Twin jet electrolytical thinning (Struers ${ }^{\circledR}$ Tenupol 5) to electron transparency in a solution of ethanol with $5 \%$ perchloric acid at approximately $-20{ }^{\circ} \mathrm{C}$ and an applied voltage of $22 \mathrm{~V}$ was used. TEM specimens were examined in a Jeol 2000 FX TEM operating with a $\mathrm{LaB}_{6}$ filament. Bright field transmission-electron microscopy images (BF TEM) were obtained from thin foil specimens to enable a microstructural characterisation of samples.

To acquire both secondary electrons micrographs and the EBSD maps by means EBSD technique specimens were prepared by mechanical grinding and polishing followed by electrolytic polishing with A2 Struers ${ }^{\circledR}$ electrolyte $(78 \mathrm{ml}$ Perchloric acid, $700 \mathrm{ml}$ Ethanol, $100 \mathrm{ml}$ Ethylenglycolmonobutylethan), at a tension of $40 \mathrm{~V}$, a flow rate of 6 (instrument setting) and a time of $15 \mathrm{sec}$ at ambient temperature. In addition, some samples were subjected to a thermal cycle and examined using a high temperature SEM equipped with laser powered heating stage $^{33}$ where in situ EBSD acquisition was performed. Initial EBSD map 
was acquired at ambient temperature. The temperature was then ramped up to $1000{ }^{\circ} \mathrm{C} \mathrm{s}^{-1}$ and

\section{Calculation of Variant Orientation Relationships}

In solid-state phase transitions, the transformation texture can be calculated from knowledge of the orientations of the parent crystals and their OR with the product phase. ${ }^{34}$ This assumes that the product phase grows in the parent crystal in which it nucleates. In a displacive transformation, the crystal structure of the parent phase is deformed into that of the product without the need for any diffusion. Since the coordinated movements of atoms associated with this transformation mechanism cannot in general be sustained across grain boundaries, it is reasonable to assume that the product is confined to the parent grain with which it has an OR. ${ }^{35}$

Displacive transformations involve the disciplined motion of atoms. As a result, there are clearly defined relationships between all aspects of the parent and product lattices. The theory for this is well established and can be found elsewhere. ${ }^{17,18}$

The description of complete crystallographic set of a single plate of martensite, includes the habit plane, the shape deformation and the OR as shown in. ${ }^{36,37}$ All of these quantities are mathematically connected and cannot in general vary independently. 
The product of the austenite orientation matrix $(\mathbf{S} \mathbf{J} \gamma)$ times the orientation relationship $(\gamma \mathbf{J}$ $\alpha$ ) results in the martensite orientation matrix (S J $\alpha$ ).

Equation (1) is valid for one variant. To obtain all 24 variants, the left side of the equation should be multiplied by the symmetry matrix $\chi_{\mathrm{n}}{ }^{36}$

$$
(S J \gamma)(\gamma J \alpha)=(S J \alpha)
$$

$$
(S J \gamma)(\gamma J \alpha) \chi_{n}=(S J \alpha)_{n}
$$

The result of equation (2) is 24 different orientation matrixes corresponding to all possible martensite variants. To reproduce the orientation of parent austenite it was chosen as area belongs to the same parent austenite grain.

For each of the martensite variant $(S J \alpha)$ the following operation was performed.

$$
(S J \gamma)_{n}=(S J \alpha)(\alpha J \gamma) \chi_{n}
$$

where

$$
(\gamma J \alpha)=(\gamma J \alpha)^{-1}
$$

Each $\alpha$ variant will produce 24 variant of austenite but, since they were found from the same austenite grain by comparing the 24 variant it is possible to realize the parent orientation of austenite.

When during the phase transformation not all possible crystallographic variants are equally selected variant selection occurs. This is because of the shape deformation of 
martensite/bainite plate may or may not comply with external stresses and can be expressed by interaction energy $\mathrm{U}^{38}$

$$
\Delta G_{m}=\sigma_{N} \zeta+\tau s
$$

where $\sigma_{N} \zeta$ is the stress component normal to the habit plane $\tau$ is the shear stress resolved on habit plane in the direction of shear. $\zeta$ and $s$ are the respective normal and shear strains associated with transformation.

\section{Results}

\subsection{Weld microstructures}

The fusion zone of specimens welded with the conventional weld wire, Figure $2 a$, consisted of proeutectoid ferrite at the prior austenite grain boundaries of the fully transformed solidification microstructure, while the remainder of the prior austenite grains consisted of interlocked acicular ferrite, cementite and non-metallic inclusions. The distribution of acicular ferrite plates does not show evidence of preferred orientation. The acicular ferrite plates were $\sim 5 \mu \mathrm{m}$ long and $1 \mu \mathrm{m}$ wide. The presence of acicular ferrite in the fusion zone, with the characteristic lenticular plate morphology observed in Figure $2 a$, was confirmed using bright field (BF) TEM, Figure $2 b$. This fusion zone microstructure was observed to have a high dislocation density. Specimens welded with the LTT weld wire, Figure $2 c$, comprised acicular ferrite and non-metallic inclusions. The observed average grain size was $\sim 7 \mu \mathrm{m}$ long and $1 \mu \mathrm{m}$ wide and they were aligned with a preferred orientation. The corresponding TEM BF micrograph is shown in Figure $2 d$, indicating an acicular ferrite plate morphology with high dislocation density. 


\subsection{Weld textures}

Figure 3 shows the macroscopic texture of the fusion zones of welds using both conventional and LTT weld wires, obtained using laboratory X-ray diffraction. The pole figures show a stronger texture in the LTT sample, with the $\{100\}$ secondary axes in particular being rotated $45^{\circ}$ from the TD towards the ND axis. Such a difference can also be observed in the reconstructed $\{111\}$ pole figures. A stronger effect for variant selection would be expected since, with a lower transformation temperature, more elastic strain will be built up due to thermal contraction in the austenite before transformation occurs.

Figure $4 a$ and $4 b$ shows an EBSD map in the fusion zone for each weld filler, both comprising acicular ferrite without any retained austenite. The highlighted region, containing material from a single prior austenite grain, was chosen for further analysis. The distribution of orientations present has been used to determine the prior austenite orientation and then the possible ferrite orientations resulting from the $\gamma \rightarrow \alpha$ transformation deduced, as observed in Fig. $4 c$ and $4 d$. The fusion zone of the conventional weld wire matches the case where no variant selection operates and all 24 variants occur. Conversely, a $100 \mathrm{MPa}$ applied compressive stress would be expected to inhibit the formation of 9 of the possible variants, leaving only 13. The pole figure thus generated for the single austenite grain does not match that observed for the conventional weld filler. In contrast, for the fusion zone manufactured using LTT filler metal two of the characteristic rings associated with occurrence of all 24 variants are incomplete, which matches the prediction for the case of an applied compressive stress.

Therefore, one can deduce that variant selection did operate during the $\gamma \rightarrow \alpha$ transformation in the LTT weld filler whereas it does not seem to have occurred in the weld manufactured using a conventional weld filler. Although this conclusion is qualitative in 
nature, it is grounded in both the local and global texture measurements. However, if larger regions are taken for study within the EBSD map, the problem becomes more complicated, due to the effect of accommodation stresses with the grain and between the transforming laths.

\subsection{In situ electron backscatter diffraction and comparison with modelling approach}

In some situations, when austenite transforms to bainite, martensite or acicular ferrite, some retained austenite is present after transformation and so it is possible to know the texture of prior austenite. However, in the present welds no retained austenite was detected by EBSD. Thus, an in situ observation of texture can provide invaluable information for the validation of transformation models and so here, such experiments on fusion zone material from the LTT weld metal were performed. At the start of the experiment, the EBSD map revealed fully ferritic initial bcc structure. Fiducial markers were used to ensure registry of the areas examined. After heating up to $1000{ }^{\circ} \mathrm{C}$ and holding at this temperature an EBSD map of austenite was collected from same region, indicating large $>30 \mu \mathrm{m}$ austenite grains. After cooling, the final microstructure consisted of ferritic grains size of $\sim 20 \mu \mathrm{m}$.

Figure $5 a$ shows the in situ EBSD map for the initial condition. The highlighted region shown was chosen for analysis in Fig. $5 b$, and a single orientation within that region extracted for clarity in Fig. $5 c$. For this single grain orientation, the Euler angles were $\left(26.5^{\circ}, 35.3^{\circ}\right.$, $31.2^{\circ}$ ). On heating to $1000{ }^{\circ} \mathrm{C}$, this region transformed to a single $\gamma$ grain, Fig. $6 a$ and $6 b$. For comparison, the austenite orientation inferre $\mathrm{d}^{20}$ from the $\alpha$ orientation originally present in this region, Fig. $5 b$, is given in Fig. $6 c$; it is readily observed that the $\alpha \rightarrow \gamma$ transformation obeyed the expected orientation relationship.

The measured EBSD map after cooling the material back into the ferritic phase field under no applied load is shown in Fig. $7 a-b$. It is observed that many more grains exist with their 
$\{001\}$ plane normal along the welding direction (LD) and that also some orientations have disappeared from the selected subregion, particularly those with the $\{001\}$ between the LD and ND. In addition, the grain size obtained on slow cooling without load was larger, and fewer orientations are observed overall. Again, the number of orientations present is less than the 24 possible and so some variant selection has occurred, compare Fig. $7 b$ and $c$. However, included among the orientations found is the orientation originally selected, Figures $7 d$ and $5 c$, which can readily be confirmed to be a permitted variant of the prior austenite grain, Fig. $7 e$.

Therefore, thermal cycling of the material into the austenite regime and back to ferrite again results in final grain orientations that obey the expected orientation relationships for each transformation. Thus, even where the transformation might traditionally be held to be reconstructive $(\alpha \rightarrow \gamma)$, the orientation relationships are obeyed, presumably because this involves the minimum movement of substitutional atoms. Then on cooling $(\gamma \rightarrow \alpha)$, again the orientation relationships are obeyed, although the original set of orientations are not necessarily recovered, for example the grain with their $\{001\}$ near the welding direction in Fig. $7 b$.

\section{Discussion}

Residual stress analysis in Murakawa et $a l .{ }^{32}$ indicates a difference between the residual stress and distortion patterns in welds manufacture using these two consumables. In both cases the microstructure consisted of acicular ferrite. One might believe that the similarity in microstructures would give rise to similar residual stress patterns. However, the lower temperature at the onset of transformation may result in higher yield strengths, different variant selection conditions and hence textures and internal shear strains, the production of 
differing amount of thermal strain prior to transformation and also differing transformation strains. $^{25-28}$

Lischewski $^{33}$ reported that the nucleation of the newly formed bcc phase during $\gamma \rightarrow \alpha$ transformation takes place predominantly at triple junctions of the austenite grains. However, the present study did not confirm these observations. The nucleation appeared to occur at austenite grain boundaries. It is notable that there is a difference in grain size after the $\alpha \rightarrow \gamma$ $\rightarrow \alpha$ transformation.

As noted by Kundu et al. ${ }^{36,39}$, the selection of certain crystallographic variants whose shape deformation relieves the applied stress can be analysed in terms of the overall Gibb's energy of the transformation, composed of its chemical $(\Delta \mathrm{Gc})$ and mechanical $(\Delta \mathrm{Gm})$ contributions. Where the interaction energy $\mathrm{U}$ (Eq. 5) is a significant contributor to $\Delta \mathrm{Gm}$ and is a large fraction of the total $\Delta \mathrm{G}=\Delta \mathrm{Gc}+\Delta \mathrm{Gm}$, then variant selection can occur and contribute to the minimization of $\mathrm{G}$ occurring at equilibrium. This analysis suggests that this condition is satisfied for the LTT wire whereas it is not for the conventional weld metal, presumably because $\Delta \mathrm{Gc}$ is smaller for the LTT wire, which is consistent with it having a lowered transformation temperature. Therefore, in designing a welding consumable that provides variant selection as a means of minimizing residual stress and distortion, $\Delta \mathrm{Gc}$ should be minimised. Such an approach provides a simplified thermodynamic approach to welding consumable design.

\section{Conclusions}

The textures and microstructures observed in GMA welds fabricated using both a conventional ferritic weld filler metal and a low transformation temperature (LTT) wire have been observed. In addition, thermal cycling through the ferrite-austenite-ferrite transformation 
has been performed suing in situ EBSD on material from the LTT weld fusion zone. The following conclusions can be drawn.

1. In both cases, acicular ferrite microstructures were obtained, and in the case of the conventional weld wire, some allotriomorphic ferrite was also observed.

2. The macroscopic textures observed in the two welds were quite different.

3. EBSD analysis of the LTT fusion zone showed evidence of variant selection consistent with an applied compressive stress in the welding direction; no such evidence was observed for the conventional welding consumable.

4. Cycling of the LTT fusion zone material through the austenite phase resulted a change in the orientations observed in a small subregion, but these variants all obeyed the expected crystallographic orientation relationships.

It is suggested that the maximisation of the mechanical contribution to the Gibbs energy of transformation and minimisation of the chemical contribution will provide a simple route to the design of welding consumables that exploit variant transformations to minimise residual stress and distortion in GMA welds. Consideration of such transformations would then need to be included in finite element models of the welding process where these are used for joint design and process optimisation.

\section{Acknowledgements}

Authors would like to thank Mrs Tatiana Gorkaya at RWTH Aachen, Germany for performing in situ EBSD maps. This research was supported by a Marie Curie Intra European Fellowship within the $7^{\text {th }}$ European Community Framework and EPSRC. 


\section{References}

1. G. E. Totten, M. A. H. Howes and T. Inoue (Eds): 'Handbook of Residual Stress and Deformation of Steel', 2002, ASM International.

2. K. Masubuchi: 'Analysis of welded structures: residual stresses, distortion, and their consequences', 1980, Oxford, Pergamon Press.

3. J. Eckerlid, T. Nilsson and L. Karlsson: 'Fatigue properties of longitudinal attachments welded using low transformation temperature filler', Sci. Technol. Weld. Join., 2003, 8, (5), 353-359.

4. J. A. Francis, H. J. Stone, S. Kundu, H. K. D. H. Bhadeshia, R. B. Rogge, P. J. Withers and L. Karlsson: 'The effects of filler metal transformation temperature on residual stresses in a high strength steel weld', J. Press. Vessel Technol.-Trans. ASME", 2009, 131, (4), 041401-041409.

5. A. Ohta, K. Matsuoka, N.T. Nguyen, Y. Maeda and N. Suzuki: 'Fatigue strength improvement of lap joints of thin steel plate using low-transformation-temperature welding wire', Am. Weld. J., 2003, 82, (4), 78-83.

6. A. Ohta, N. Suzuki, Y. Maeda, K. Hiraoka and T. Nakamura: 'Superior fatigue crack growth properties in newly developed weld metal', Int. J. Fatigue, 1999, 21, S113S118.

7. A. Ohta, O. Watanabe, K. Matsuoka, C. Shiga, S. Nishijima, Y. Maeda, N. Suzuki, and T. Kubo: 'Fatigue strength improvement by using newly developed low transformation temperature welding material', Weld World, 1999, 43, (6), 38-42.

8. A. A. Shirzadi, H. K. D. H. Bhadeshia, L. Karlsson and P. J. Withers: 'Stainless steel weld metal designed to mitigate residual stresses', Sci. Technol. Weld. Join., 2009, 14, (6), 559-565. 
9. S. Zenitani, N. Hayakawa, J. Yamamoto, K. Hiraoka, Y. Morikage, T. Kubo, K. Yasuda and K. Amano: 'Development of new low transformation temperature welding consumable to prevent cold cracking in high strength steel welds', Sci. Technol. Weld. Join., 2007, 12, (6), 516-522.

10. H. K. D. H. Bhadeshia: 'Possible effects of stress on steel weld microstructures', 'Mathematical Modelling of Weld Phenomena', $2^{\text {nd }}$ edn, 1995, United Kingdom, Institute of Materials.

11. J. A. Francis, H. J. Stone, S. Kundu, R. B. Rogge, H. K. D. H. Bhadeshia, P. J. Withers and L. Karlsson: 'Transformation temperatures and welding residual stresses in ferritic steels', Proc. ASME Pressure Vessels and Piping Division Conference, San Antonio, Texas, USA, July 2007, American Society of Mechanical Engineers, 949956.

12. Y. Mikami, Y. Morikage, M. Mochizuki and M. Toyoda: 'Angular distortion of fillet welded T joint using low transformation temperature welding wire', Sci. Technol. Weld. Join., 2009, 14, (2), 97-105.

13. J. Romero, M. Preuss and J. Quinta da Fonseca: 'Texture memory and variant selection during phase transformation of a zirconium alloy', Acta Mater., 2009, 57, (18), 5501-5511.

14. H. R. Wenk, I. Lonardelli and D. Williams: 'Texture changes in the hep RT bcc RT hcp transformation of zirconium studied in situ by neutron diffraction', Acta Mater., 2004, 52, (7), 1899-1907.

15. M. Karadge, M. Preuss, C. Lovell, P. J. Withers and S. Bray: 'Texture development in Ti-6Al-4V linear friction welds', Mater. Sci. Eng.: A., 2007, A459, (1-2), 182-191. 
16. N. Yoshinaga, H. Inoue, K. Kawasaki, L. Kestens and B. C. De Cooman: 'Factors Affecting Texture Memory Appearing through alpha - > gamma - > alpha Transformation in IF Steels', Mater. Trans., 2007, 48, (8), 2036-2042.

17. J. S. Bowles and J. K. Mackenzie: 'The crystallography of martensite transformations I', Acta Metall., 1954, 2, (1), 129-137.

18. J. K. Mackenzie and J. S. Bowles: 'The crystallography of martensite transformations II', Acta Metall., 1954, 2, (1), 138-147.

19. M. S. Wechsler, D. S. Lieberman and T. A. Read: 'On the theory of the formation of martensite', Trans. AIME J. Metals, 1953, 197, 1503-1515.

20. Kundu, S., 'Transformation strain and crystallographic texture in steels', $\mathrm{PhD}$ thesis, University of Cambridge, Cambridge, UK, 2007.

21. S. Kundu and H. K. D. H. Bhadeshia: 'Transformation texture in deformed stainless steel', Scrip. Mater., 2006, 55, (9), 779-781.

22. H. K. D. H. Bhadeshia, H.F.G. Abreu and S. Kundu: 'Calculation of crystallographic Texture due to Displacive Transformations', Int. J. Mater. Res., 2008, 99, (4), 342346.

23. S. Kundu and H. K. D. H. Bhadeshia: 'Crystallographic texture and intervening transformation', Scrip. Mater., 2007, 57, (9), 869-872.

24. S. S. Babu and H. K. D. H. Bhadeshia: 'Stress and the acicular ferrite transformation', Mater. Sci. Eng.: A., 1992, A156, (1), 1-9.

25. J. C. Bokros and E. R. Parker: 'The mechanism of the martensite burst transformation in Fe-Ni single crystals', Acta Metall., 1963, 11, (12), 1291-1301.

26. S. Chatterjee, H. S. Wang, J. R. Yang and H. K. D. H. Bhadeshia: 'Mechanical stabilisation of austenite', Mater. Sci. Technol., 2006, 22, (6), 641-644. 
27. T. N. Durlu and J. W. Christian: 'Effect of prior deformation on the martensite burst transformation in single crystals of an Fe-Ni-C alloy', Acta Metall., 1979, 27, (4), 663666.

28. K. Hase, C. Garcia-Mateo and H. K. D. H. Bhadeshia: 'Bainite formation influenced by large stress', Mater. Sci. Technol., 2004, 20, (12), 1499-1505.

29. C. M. Davies, M. Béreš, D. Hughes, D. Dye and K. M. Nikbin: 'The Influence of Geometric and Welding Parameters on Residual Stress in Thin Welded Steel Structures', Proc. ASME Pressure Vessels and Piping Division Conference, Prague, Czech Republic, July, 2009.

30. C. M. Davies, R. C. Wimpory, M. Béreš, M. P. Lightfoot, D. Dye, E. Oliver, N. P. O'Dowd, G. J. Bruce and K. M. Nikbin: 'The effect of residual stress and microstructure on distortion in thin welded steel plates', Proc. ASME Pressure Vessels and Piping Division Conference, San Antonio, Texas, USA, July 2007, American Society of Mechanical Engineers.

31. C. M. Davies, R. C. Wimpory, D. Dye and Nikbin: 'The effect of plate dimensions on residual stresses in welded thin steel plates', Proceedings of the ASME Pressure Vessels and Piping Conference, New York, NY, v. 6, 309-319, 2009.

32. H. Murakawa, M. Béreš, C. M. Davies, S. Rashed, A. Vega, M. Tsunori, K. M. Nikbin and D. Dye: 'The Effect of Low Transformation Temperature Weld Filler Metal on Welding Residual Stress', Sci. Technol. Weld. Join., 2010, 15, 393-399.

33. I. Lischewski, D. M. Kirch, A. Ziemons and G. Gottstein: 'Investigation of the $\alpha-\gamma-\alpha$ Phase Transformation in Steel: High-Temperature In situ EBSD Measurements', Texture, Stress, and Microstructure, 2008. DOI:10.1155/2008/294508.

34. H. J. Bunge, M. Humbert and P. I. Welch: 'Texture transformation with variant selection', Scrip. Metall., 1983, 17, (12), 1403-1405. 
35. H. K. D. H. Bhadeshia, H.F.G. Abreu and S. Kundu: 'Crystallographic Texture due to Displacive Transformations', Int. J. Mater. Res., 2008, 99, (4), 342-346.

36. A. A. Shirzadi, H.F.G. Abreu, L. Pocock, D. Klobčar, P. J. Withers and H. K. D. H. Bhadeshia: 'Bainite Orientation in Plastically Deformed Austenite', Int. J. Mater. Res., 2009, 100, 40-45.

37. H. K. D. H. Bhadeshia: 'Bainite in steels: transformations, microstructure and properties', $2^{\text {nd }}$ edn, Vol. 1, 2001, London, IOM Communications.

38. S. Kundu, K. Hase and H. K. D. H. Bhadeshia: 'Crystallographic texture of stressaffected bainite', Proc. Royal Society A: Mathematical, Physical and Engineering Science, 2007, v. 463, n. 2085, p. 2309-2328.

39. H. K. D. H. Bhadeshia, S. A. David, J. M. Vitek and R. W. Reed: 'Stress induced transformation to bainite in FeCrMoC pressure vessel steel', Mater. Sci. Technol., 1991, 7, (8), 686-698. 


\section{Tables}

Table 1 Chemical composition (wt. \%) of steel plate, conventional weld wire and LTT weld wire [32].

\begin{tabular}{llllllllll}
\hline & $\mathrm{C}$ & $\mathrm{Si}$ & $\mathrm{Mn}$ & $\mathrm{P}$ & $\mathrm{S}$ & $\mathrm{Cu}$ & $\mathrm{Ni}$ & $\mathrm{Cr}$ & $\mathrm{Nb}$ \\
\hline Steel plate & 0.11 & 0.18 & 1.29 & 0.01 & 0.004 & 0.02 & 0.03 & 0.03 & 0.01 \\
$\mathrm{CW}$ & 0.07 & 0.61 & 1.42 & 0.01 & 0.010 & 0.14 & 0.04 & 0.02 & 0.02 \\
LTTW & 0.04 & 0.32 & 0.36 & 0.008 & 0.004 & 0.15 & 11.9 & - & - \\
\hline
\end{tabular}

Table 2 Welding parameters

\begin{tabular}{lllllll}
\hline & Weld & Weld & Weld & Weld & Heat & Parameter \\
& length & Speed & Current & voltage & input & $\mathrm{Q} / \mathrm{h}^{2}$ \\
& {$[\mathrm{~mm}]$} & {$\left[\mathrm{mm} \mathrm{s}^{-1}\right]$} & {$[\mathrm{A}]$} & {$[\mathrm{V}]$} & {$\left[\mathrm{kJ} \mathrm{mm}^{-1}\right]$} & {$\left[\mathrm{J} \mathrm{mm}^{-3}\right]$} \\
\hline $\mathrm{CW}$ & 500 & 2.7 & 150 & 18 & 1.00 & 62.5 \\
LTTW & 500 & 3.5 & 180 & 20 & 1.03 & 64.3 \\
\hline
\end{tabular}




\section{Figures}

Figure 1 Macrograph fusion zone and heat affected zone of conventional weld wire.

Figure 2 SEM-SE (left) and TEM-BF (right) micrographs of $a$ and $b$ conventional weld wire; $c$ and $d$ LTT weld wire.

Figure 3 Measured macroscopic texture of the fusion zones from welds manufacture using $a$ the conventional weld wire and $b$ the LTT weld wire.

Figure 4 EBSD inverse pole figure (IPF) map with selected subset of $a$ conventional weld wire and $b$ LTT weld wire, $c$ comparison of experimentally determined $\{100\}$ pole figures in highlighted subregion of $a$ with computed $\{100\}$ pole figures following $\alpha \rightarrow \gamma \rightarrow \alpha$ transformation, $d$ the same comparison as in $c$ but considering subregion of $b$. Exp denotes experimental, Calc calculated and $13 \mathrm{~V}$ number of variants considered in the computation.

Figure 5 In situ EBSD map for the initial, ferritic condition $a$, measured orientations for the highlighted subregion $b$, and for a single orientation within the subregion $c$.

Figure 6 In situ EBSD map for the same region as Figure 5, after heating to $1000{ }^{\circ} \mathrm{C}$ and transformation to austenite, $a$. Also shown, $b$ is the measured austenite orientation for the subregion highlighted, which is the same region as in Figure $7 a$ and $c$ calculated Pole Figure from one grain within the highlighted region in Figure $5 a$ following $\alpha \rightarrow \gamma$ transformation. 
Figure 7 In situ EBSD map, $a$, after cooling back to the ferritic phase field at $70{ }^{\circ} \mathrm{C}$, and $b$ measured bcc orientations in the highlighted subregion, which is the same region as in Figures 5 and 6. In $c$, the calculated possible bcc orientations are shown for all 24 variants formed from the initial fcc orientation shown in Figure $6 b$ and $a$. These include the orientation shown in $e$, which is one of the orientations observed in the highlighted subregion, $d$ after $\alpha \rightarrow \gamma \rightarrow \alpha$ transformation. 
Dear Professor DebRoy,

We are very pleased to hear that our work is found to be of interest and is likely to be suitable for publication in Science and Technology of Welding and Joining.

Please find our response to the comments from the Reviewer

With kind regards

Prof. Hamilton Ferreira Gomes de Abreu

Reviewer \# 1: The paper has applied in-situ EBSD to analyze the variant selection. Although, it would have been nice to perform the in-situ EBSD in both LTT and Conventional wire, I believe the work merits the publications and will provide the needed information for designing the LTT welding consumables.

minor comments are given below:

(1) The LTT transformation is named as acicular ferrite, is it not martensitic due to high Nickel content?

Page 7, line 59 after text "indicating an acicular ferrite plate morphology with high dislocation density" included text:

One might expect a martensitic microstructure in the sample welded with the high $\mathrm{Ni}$ content LTT weld consumable. However, acicular ferrite morphology was observed in the fusion zone, which was confirmed by both the TEM and SEM. The formation of acicular ferrite is presumably due to the reduced cooling rate in thin $(4 \mathrm{~mm})$ plates, where the heat transfer is much lower compared to that in thick plate preventing formation of martensite. Another issue is the weld metal dilution level in dissimilar weld joint. Although $\mathrm{Ni}$ content in the LTT consumable is $11.9 \mathrm{wt} . \mathrm{\%}$, this will be reduced due to the metal dilution leading to decreased stability of austenite.

The authors state that $\mathbf{4 2 0}$ deg-c as the transformation start.. Is it below the Ms or above the Ms temperature?

Page 3, line 41 after text "temperature (LTT) i.e. $420^{\circ} \mathrm{C}$ were used in the fabrication of the welds." included text "the latter is above the Ms temperature calculated according Ishida. ${ }^{33}$ "and reference 33

Explanation:

1. Considering the equation 21 in work of Ishida ref. [33] Martensite start (Ms) temperature of $366^{\circ} \mathrm{C}$ was determined. The transformation start temperature of $420^{\circ} \mathrm{C}$ is above the calculated Ms temperature.

Ref. 33: K. Ishida: 'Calculation of the effect of alloying elements on the Ms temperature in steels', J. Alloys and Comp., 1995, 220, (1), 126-131.

(2) Also when did the authors see the transformation start during cooling down to room temperature. 
Page 5 , line 7 after text " $70{ }^{\circ} \mathrm{C}$ the EBSD transformation texture was acquired" included text:

"No transformation behaviour was studied during cooling in SEM. The in-situ EBSD pattern were acquired at $1000^{\circ} \mathrm{C}$ and $70^{\circ} \mathrm{C}$ only"

\section{Why was the decision made to measure the transformation at $70^{\circ} \mathrm{C}$.}

Page 5 , line 5 after text "cooling of samples from $1000{ }^{\circ} \mathrm{C}$ to $500{ }^{\circ} \mathrm{C}$ with rate of approximately $15^{\circ} \mathrm{C} \mathrm{s}^{-1}$

included text

"The EBSD data were collected at $70{ }^{\circ} \mathrm{C}$, at which the transformation process is completed and where a fully transformed bcc structure is present. No further changes in the microstructure below this temperature was observed."

\section{(3) Can authors comment on the feasibility of detecting the transformation with stress during in-situ EBSD?}

This comment is not included in the manuscript.

It would be quite challenging to detect the transformation with stress during in-situ EBSD. To track e.g. displacive transformation process under stress would require much faster EBSD systems allowing a continuous acquisition. The acquisition rate of the current EBSD systems is on the order of minutes which is much longer than the duration of the displacive transformation (order of sec.). In addition, the surface relief developed during displacive transformation and deformed grains would impair the quality of the data collected.

(4) It will be nice if authors can provide the details of the experimental technique, like how they heated with laser and cooled within SEM? Is it only surface heating etc.

Page 4, line 59 after text “where in situ EBSD acquisition was performed.” included text

The laser powered heating stage consisted of a SiC sample holder in addition to inner and outer heating shields. The sample was mounted onto the holder by a tungsten clamp. A continuous wave infrared laser light of wavelength $810 \mathrm{~nm}$ and maximum power output of $100 \mathrm{~W}$ was used to heat the SiC sample holder by absorption only. To ensure high-temperature stability, the inner heating shield is made of unchilled tantalum sheets. The outer heating shield is made of copper and it is cooled together with the copper base of the heating stage by an integrated water cooling circuit. A detailed description of the assembly may be found in ref. ${ }^{34}$

(5) Also the reverse transformation memory during alpha to gamma to alpha transformation has been studied in boron containing $\mathrm{Cr}-\mathrm{Mo}$ welds. These results may be relevant to the current paper too.

This reference is now in our manuscript.

Page 10 line 16 after text "It is notable that there is a difference in grain size after the $\alpha \rightarrow \gamma$

$\rightarrow \alpha$ transformation.” included text and ref 40 
"Shirane et $a l^{40}$ demonstrated that a martensitic ferrite to austenite reverse transformation takes place in B containing 9\% Cr steel. In contrary to this work, the LTT weld consumable used in the work present does exhibit a diffusional reverse transformation observed during in-situ EBSD experiment.”

Ref. 40. T. Shirane, S. Tsukamoto, Y. Adachi, T. Hanamura, M. Shimizu, F. Abe: 'Ferrite to austenite reverse transformation process in B containing 9\% Cr heat resistant steel HAZ', Sci. Technol. Weld. Join., 2009, 14, (8), 698-707. 
Dear Professor DebRoy,

We are very pleased to hear that our work is found to be of interest and is likely to be suitable for publication in Science and Technology of Welding and Joining.

Please find our response to the comments from the Reviewer

With kind regards

Prof. Hamilton Ferreira Gomes de Abreu

Reviewer \#1: The paper has applied in-situ EBSD to analyze the variant selection. Although, it would have been nice to perform the in-situ EBSD in both LTT and Conventional wire, I believe the work merits the publications and will provide the needed information for designing the LTT welding consumables.

minor comments are given below:

(1) The LTT transformation is named as acicular ferrite, is it not martensitic due to high Nickel content?

Page 7, line 59 after text "indicating an acicular ferrite plate morphology with high dislocation density" included text:

One might expect a martensitic microstructure in the sample welded with the high Ni content LTT weld consumable. However, acicular ferrite morphology was observed in the fusion zone, which was confirmed by both the TEM and SEM. The formation of acicular ferrite is presumably due to the reduced cooling rate in thin $(4 \mathrm{~mm})$ plates, where the heat transfer is much lower compared to that in thick plate preventing formation of martensite. Another issue is the weld metal dilution level in dissimilar weld joint. Although $\mathrm{Ni}$ content in the LTT consumable is $11.9 \mathrm{wt} .-\%$, this will be reduced due to the metal dilution leading to decreased stability of austenite.

The authors state that 420 deg-c as the transformation start.. Is it below the Ms or above the Ms temperature?

Page 3, line 41 after text "temperature (LTT) i.e. $420{ }^{\circ} \mathrm{C}$ were used in the fabrication of the welds." included text "the latter is above the Ms temperature calculated according Ishida. ${ }^{33}$ " and reference 33

Explanation:

1. Considering the equation 21 in work of Ishida ref. [33] Martensite start (Ms) temperature of $366^{\circ} \mathrm{C}$ was determined. The transformation start temperature of $420^{\circ} \mathrm{C}$ is above the calculated Ms temperature.

Ref. 33: K. Ishida: 'Calculation of the effect of alloying elements on the Ms temperature in steels', J. Alloys and Comp., 1995, 220, (1), 126-131.

(2) Also when did the authors see the transformation start during cooling down to room temperature.

Page 5, line 7 after text " $70{ }^{\circ} \mathrm{C}$ the EBSD transformation texture was acquired" included text:

"No transformation behaviour was studied during cooling in SEM. The in-situ EBSD pattern were acquired at $1000^{\circ} \mathrm{C}$ and $70^{\circ} \mathrm{C}$ only" 


\section{Why was the decision made to measure the transformation at $70^{\circ} \mathrm{C}$.}

Page 5, line 5 after text "cooling of samples from $1000{ }^{\circ} \mathrm{C}$ to $500{ }^{\circ} \mathrm{C}$ with rate of approximately $15^{\circ} \mathrm{C}$ $s^{-1}$

included text

"The EBSD data were collected at $70^{\circ} \mathrm{C}$, at which the transformation process is completed and where a fully transformed bcc structure is present. No further changes in the microstructure below this temperature was observed."

(3) Can authors comment on the feasibility of detecting the transformation with stress during in-situ EBSD?

This comment is not included in the manuscript.

It would be quite challenging to detect the transformation with stress during in-situ EBSD. To track e.g. displacive transformation process under stress would require much faster EBSD systems allowing a continuous acquisition. The acquisition rate of the current EBSD systems is on the order of minutes which is much longer than the duration of the displacive transformation (order of sec.). In addition, the surface relief developed during displacive transformation and deformed grains would impair the quality of the data collected.

(4) It will be nice if authors can provide the details of the experimental technique, like how they heated with laser and cooled within SEM?

Is it only surface heating etc.

Page 4, line 59 after text "where in situ EBSD acquisition was performed." included text

The laser powered heating stage consisted of a $\mathrm{SiC}$ sample holder in addition to inner and outer heating shields. The sample was mounted onto the holder by a tungsten clamp. A continuous wave infrared laser light of wavelength $810 \mathrm{~nm}$ and maximum power output of $100 \mathrm{~W}$ was used to heat the SiC sample holder by absorption only. To ensure high-temperature stability, the inner heating shield is made of unchilled tantalum sheets. The outer heating shield is made of copper and it is cooled together with the copper base of the heating stage by an integrated water cooling circuit. A detailed description of the assembly may be found in ref. ${ }^{34}$

(5) Also the reverse transformation memory during alpha to gamma to alpha transformation has been studied in boron containing $\mathrm{Cr}$-Mo welds. These results may be relevant to the current paper too.

This reference is now in our manuscript.

Page 10 line 16 after text "It is notable that there is a difference in grain size after the $\alpha \rightarrow \gamma$

$\rightarrow \alpha$ transformation." included text and ref 40

"Shirane et al. ${ }^{40}$ demonstrated that a martensitic ferrite to austenite reverse transformation takes place in B containing 9\% Cr steel. In contrary to this work, the 
LTT weld consumable used in the work present does exhibit a diffusional reverse transformation observed during in-situ EBSD experiment."

Ref. 40. T. Shirane, S. Tsukamoto, Y. Adachi, T. Hanamura, M. Shimizu, F. Abe: 'Ferrite to austenite reverse transformation process in $\mathrm{B}$ containing $9 \% \mathrm{Cr}$ heat resistant steel HAZ', Sci. Technol. Weld. Join., 2009, 14, (8), 698-707. 


\title{
The effect of variant transformations in the fusion zones of gas metal arc welds
}

\begin{abstract}
The macro- and microtextures of gas metal arc (GMA / GMAW) welds fabricated using both conventional ferritic and low transformation (LTT) filler metals were examined. Both welds were largely composed of acicular ferrite. The weld textures were found to be distinct, which is observed to be due to variant selection during the austenite-to-ferrite transformation. In situ EBSD performed on thermal cycling of the LTT fusion zone into the austenite phase field confirmed that these transformations satisfy the expected crystallographic relationships. Implications for welding consumable design and finite element process modelling are drawn.
\end{abstract} Keywords: Texture analysis; Displacive transformation; Variant selection; Gas Metal Arc Weld.

\section{Introduction}

The thermal strains that arise during welding give rise to residual stresses and distortion in welded joints that are problematic, both in initial fabrication of a satisfactory structure and its subsequent strength, fatigue and stress-corrosion cracking performance. ${ }^{1,2}$ However, in the majority of welds a filler metal is added and therefore the possibility exists to select a filler material with the aim of improving the performance of the welded joint. Over recent years, here has been much interest in using filler metals during the welding of steels that exploit the austenite-to-ferrite $(\gamma \rightarrow \alpha)$ transformation strains to absorb some of the thermal strains from welding, mitigating the residual stress and distortion. ${ }^{3-9}$ It has been shown that weld fabrication using, for example, filler metal wires with a lowered $\gamma \rightarrow \alpha$ transformation temperature (so-called low transformation temperature or LTT wires) can result in lowered residual stresses and distortion. ${ }^{8,10-12}$ 
Where the transformation is entirely reconstructive, one might initially believe that the transformation strain will simply be due to the volume change between the two unit cells. However, for a fully displacive transformation, one must consider if the applied stress state can bias which orientations of the product phase form from the parent - in the case of the $\gamma \rightarrow \alpha$ transformation 24 crystallographic variants of the bcc/bct ferritic (bainite or martensite) phase can form from the austenite.

However, even for fully reconstructive transformations some 'memory' is commonly observed in the product phase textures. For example, in $\mathrm{Zr}$ and $\mathrm{Ti}$ it is now commonly accepted that the simultaneous satisfaction of the orientation relationship (OR) at the parent phase grain boundary by the product phase can result in a memory effect. ${ }^{13-15}$ Such an effect has also been observed in the macroscopic textures observed using in situ synchrotron diffraction in a interstitial-free (IF) steel. ${ }^{16}$

For displacive transformations the OR between the two phases is complicated by the possibility to minimise the strain at the interface plane by slight rotations from the ideal OR, as shown by Mackenzie and Bowles ${ }^{17,18}$ and Wechsler et al. ${ }^{19}$ in the phenomenological theory of martensite crystallography. The overall transformation elastic strain tensor can be calculated and compare to the applied stress, resulting in a calculation of which variants are favoured by the applied stress state. ${ }^{20-23}$ Bhadeshia $^{10}$ showed that the volume change due to the transformation in bainite is much smaller than the shear component. Babu and Bhadeshia ${ }^{24}$ studied the effect of applied stress on the formation of acicular ferrite. In series of heat treatment experiments and subsequent microstructural observations they revealed at least six crystallographic variants form where no stress is applied and that many fewer are observed when the transformation occurs under an applied elastic load. Of course, plastic strains can also have an effect by favouring variants that grow across slip planes and by the hindering of plate growth by plastic damage. ${ }^{25-27}$ 
Hase $e t a l{ }^{28}$ examined the influence of stress on the transformation kinetics of upper bainite. It was found that compressive stresses of 4-200 MPa strongly favoured the growth of compliant variants, potentially even leading to large regions of bainite in identical orientations. In addition, they demonstrated that the stress increases the bainite start temperature and accelerates the kinetics of the transformation.

In the present paper, we demonstrate that these effects do operate in LTT filler metal, but that the effect is not discernible in conventional weld filler (CW), and so that these transformations are relevant to weld models for the mitigation of residual stress and distortion using LTT fillers. The macro- and micro- textures have been observed in LTT and CW welds and fusion zone material from these welds is then characterised using in situ electron backscatter diffraction (EBSD) during thermal cycling.

\section{Experimental Description}

Weld samples were fabricated using manual gas metal arc welding (GMAW) procedure. ${ }^{29-}$ ${ }^{31}$ Two high strength low alloy steel plates of dimensions $500 \mathrm{~mm}$ long, $250 \mathrm{~mm}$ wide and 4 $\mathrm{mm}$ in thickness were single pass butt welded. A conventional weld wire $(\mathrm{CW})$ with high transformation temperature i.e. $560{ }^{\circ} \mathrm{C}$, and a consumable with a low transformation temperature (LTT) i.e. $420{ }^{\circ} \mathrm{C}$ were used in the fabrication of the welds, ${ }^{32}$ the latter is above the Ms temperature calculated according Ishida. ${ }^{33}$ Plates were held apart by series of three tack welds $25 \mathrm{~mm}$ long which were located in the plate centre and at the both ends. Ceramic backing tiles were used to contain the weld pool. During welding, plates were unrestrained and rested on wooden pallets. The chemical compositions of the plates and the weld consumables are shown in Table 1. The welding was performed using parameters shown in Table 2. Residual stresses in the welded plates were measured employing the neutron diffraction technique and were reported in. ${ }^{29,31,32}$ The results indicates, remarkably different 
residual stress pattern in longitudinal direction. While in the fusion zone and its vicinity of plates welded with $\mathrm{CW}$ wire, tensile stresses of magnitude $440 \mathrm{MPa}$ were developed, in the LTT filler compressive stresses of around $100 \mathrm{MPa}$ are present. Macrograph from plate welded with conventional weld wire, Figure 1, shows width of fusion zone and heat affected zone which is approximately $10 \mathrm{~mm}$ and $20 \mathrm{~mm}$, respectively. The shape of the weld on the lower side replicates the contours of ceramic backing tiles used during the welding. It is also obvious that, the weld does not fill the gap fully on the upper side.

All of the microstructural observations including conventional transmission electron microscopy (TEM), scanning electron microscopy (SEM) and electron backscattering diffraction (EBSD) were carried out in longitudinal direction of specimens extracted from the butt welded plate (i.e. in weld cross-section). For TEM examinations, specimens were cut about $1 \mathrm{~mm}$ in thickness. The specimens were ground on $\mathrm{SiC}$ paper up to 1200 grade down to a thickness of $200 \mu \mathrm{m}$. The final foil specimens for TEM were prepared from punched $3 \mathrm{~mm}$ discs, after fine grinding on $\mathrm{SiC}$ paper up to 4000 grade down to a thickness of about $50 \mu \mathrm{m}$. Twin jet electrolytical thinning (Struers® Tenupol 5) to electron transparency in a solution of ethanol with $5 \%$ perchloric acid at approximately $-20{ }^{\circ} \mathrm{C}$ and an applied voltage of $22 \mathrm{~V}$ was used. TEM specimens were examined in a Jeol 2000 FX TEM operating with a LaB 6 filament. Bright field transmission-electron microscopy images (BF TEM) were obtained from thin foil specimens to enable a microstructural characterisation of samples.

To acquire both secondary electrons micrographs and the EBSD maps by means EBSD technique specimens were prepared by mechanical grinding and polishing followed by electrolytic polishing with A2 Struers ${ }^{\circledR}$ electrolyte $(78 \mathrm{ml}$ Perchloric acid, $700 \mathrm{ml}$ Ethanol, $100 \mathrm{ml}$ Ethylenglycolmonobutylethan), at a tension of $40 \mathrm{~V}$, a flow rate of 6 (instrument setting) and a time of $15 \mathrm{sec}$ at ambient temperature. In addition, some samples were subjected to a thermal cycle and examined using a high temperature SEM equipped with laser 
powered heating stage ${ }^{34}$ where in situ EBSD acquisition was performed. The laser powered heating stage consisted of a SiC sample holder in addition to inner and outer heating shields. The sample was mounted onto the holder by a tungsten clamp. A continuous wave infrared laser light of wavelength $810 \mathrm{~nm}$ and maximum power output of $100 \mathrm{~W}$ was used to heat the $\mathrm{SiC}$ sample holder by absorption only. To ensure high-temperature stability, the inner heating shield is made of unchilled tantalum sheets. The outer heating shield is made of copper and it is cooled together with the copper base of the heating stage by an integrated water cooling circuit. A detailed description of the assembly may be found in Lischewski. ${ }^{34}$ Initial EBSD map was acquired at ambient temperature. The temperature was then ramped up to $1000{ }^{\circ} \mathrm{C} \mathrm{s}^{-}$ ${ }^{1}$ and an acquisition of austenite EBSD map was performed. Following this, the laser was switch off allowed cooling of samples from $1000{ }^{\circ} \mathrm{C}$ to $500{ }^{\circ} \mathrm{C}$ with rate of approximately 15 ${ }^{\circ} \mathrm{C} \mathrm{s}^{-1}$. At $70{ }^{\circ} \mathrm{C}$ the EBSD transformation texture was acquired. The EBSD data were collected at $70{ }^{\circ} \mathrm{C}$, at which the transformation process is completed and where a fully transformed bcc structure is present. No further changes in the microstructure below this temperature was observed. Subsequent data analysis was carried out using HKL's Technology "Channel 5" software.

Macrotexture measurements were performed by means of X-ray diffraction technique and the data obtained were inputted into the texture analysis software popLA (preferred orientation package - Los Alamos) to plot the pole figures.

\section{Calculation of Variant Orientation Relationships}

In solid-state phase transitions, the transformation texture can be calculated from knowledge of the orientations of the parent crystals and their OR with the product phase. ${ }^{35}$ This assumes that the product phase grows in the parent crystal in which it nucleates. In a displacive transformation, the crystal structure of the parent phase is deformed into that of the 
product without the need for any diffusion. Since the coordinated movements of atoms associated with this transformation mechanism cannot in general be sustained across grain boundaries, it is reasonable to assume that the product is confined to the parent grain with which it has an OR. ${ }^{36}$

Displacive transformations involve the disciplined motion of atoms. As a result, there are clearly defined relationships between all aspects of the parent and product lattices. The theory for this is well established and can be found elsewhere. ${ }^{17,18}$

The description of complete crystallographic set of a single plate of martensite, includes the habit plane, the shape deformation and the OR as shown in. ${ }^{37,38}$ All of these quantities are mathematically connected and cannot in general vary independently.

The product of the austenite orientation matrix $(\mathbf{S ~ J} \gamma)$ times the orientation relationship $(\gamma \mathbf{J}$ $\alpha)$ results in the martensite orientation matrix (S J $\alpha$ ).

Equation (1) is valid for one variant. To obtain all 24 variants, the left side of the equation should be multiplied by the symmetry matrix $\chi_{\mathrm{n}}{ }^{37}$

$$
\begin{aligned}
& (S J \gamma)(\gamma J \alpha)=(S J \alpha) \\
& (S J \gamma)(\gamma J \alpha) \chi_{n}=(S J \alpha)_{n}
\end{aligned}
$$

The result of equation (2) is 24 different orientation matrixes corresponding to all possible martensite variants. To reproduce the orientation of parent austenite it was chosen as area belongs to the same parent austenite grain.

For each of the martensite variant $(S J \alpha)$ the following operation was performed.

$$
(S J \gamma)_{n}=(S J \alpha)(\alpha J \gamma) \chi_{n}
$$


where

$$
(\gamma J \alpha)=(\gamma J \alpha)^{-1}
$$

Each $\alpha$ variant will produce 24 variant of austenite but, since they were found from the same austenite grain by comparing the 24 variant it is possible to realize the parent orientation of austenite.

When during the phase transformation not all possible crystallographic variants are equally selected variant selection occurs. This is because of the shape deformation of martensite/bainite plate may or may not comply with external stresses and can be expressed by interaction energy $\mathrm{U}^{39}$

$$
\Delta G_{m}=\sigma_{N} \zeta+\tau s
$$

where $\sigma_{N} \zeta$ is the stress component normal to the habit plane $\tau$ is the shear stress resolved on habit plane in the direction of shear. $\zeta$ and $s$ are the respective normal and shear strains associated with transformation.

\section{Results}

\subsection{Weld microstructures}

The fusion zone of specimens welded with the conventional weld wire, Figure $2 a$, consisted of proeutectoid ferrite at the prior austenite grain boundaries of the fully transformed solidification microstructure, while the remainder of the prior austenite grains consisted of interlocked acicular ferrite, cementite and non-metallic inclusions. The 
distribution of acicular ferrite plates does not show evidence of preferred orientation. The acicular ferrite plates were $\sim 5 \mu \mathrm{m}$ long and $1 \mu \mathrm{m}$ wide. The presence of acicular ferrite in the fusion zone, with the characteristic lenticular plate morphology observed in Figure $2 a$, was confirmed using bright field (BF) TEM, Figure $2 b$. This fusion zone microstructure was observed to have a high dislocation density. Specimens welded with the LTT weld wire, Figure $2 c$, comprised acicular ferrite and non-metallic inclusions. The observed average grain size was $\sim 7 \mu \mathrm{m}$ long and $1 \mu \mathrm{m}$ wide and they were aligned with a preferred orientation. The corresponding TEM BF micrograph is shown in Figure $2 d$, indicating an acicular ferrite plate morphology with high dislocation density. One might expect a martensitic microstructure in the sample welded with the high Ni content LTT weld consumable. However, acicular ferrite morphology was observed in the fusion zone, which was confirmed by both the TEM and SEM. The formation of acicular ferrite is presumably due to the reduced cooling rate in thin $(4 \mathrm{~mm})$ plates, where the heat transfer is much lower compared to that in thick plate preventing formation of martensite. Another issue is the weld metal dilution level in dissimilar weld joint. Although Ni content in the LTT consumable is 11.9 wt.- $\%$, this will be reduced due to the metal dilution leading to decreased stability of austenite.

\subsection{Weld textures}

Figure 3 shows the macroscopic texture of the fusion zones of welds using both conventional and LTT weld wires, obtained using laboratory X-ray diffraction. The pole figures show a stronger texture in the LTT sample, with the $\{100\}$ secondary axes in particular being rotated $45^{\circ}$ from the TD towards the ND axis. Such a difference can also be observed in the reconstructed $\{111\}$ pole figures. A stronger effect for variant selection would be expected since, with a lower transformation temperature, more elastic strain will be built up due to thermal contraction in the austenite before transformation occurs. 
Figure $4 a$ and $4 b$ shows an EBSD map in the fusion zone for each weld filler, both comprising acicular ferrite without any retained austenite. The highlighted region, containing material from a single prior austenite grain, was chosen for further analysis. The distribution of orientations present has been used to determine the prior austenite orientation and then the possible ferrite orientations resulting from the $\gamma \rightarrow \alpha$ transformation deduced, as observed in Fig. $4 c$ and $4 d$. The fusion zone of the conventional weld wire matches the case where no variant selection operates and all 24 variants occur. Conversely, a $100 \mathrm{MPa}$ applied compressive stress would be expected to inhibit the formation of 9 of the possible variants, leaving only 13 . The pole figure thus generated for the single austenite grain does not match that observed for the conventional weld filler. In contrast, for the fusion zone manufactured using LTT filler metal two of the characteristic rings associated with occurrence of all 24 variants are incomplete, which matches the prediction for the case of an applied compressive stress.

Therefore, one can deduce that variant selection did operate during the $\gamma \rightarrow \alpha$ transformation in the LTT weld filler whereas it does not seem to have occurred in the weld manufactured using a conventional weld filler. Although this conclusion is qualitative in nature, it is grounded in both the local and global texture measurements. However, if larger regions are taken for study within the EBSD map, the problem becomes more complicated, due to the effect of accommodation stresses with the grain and between the transforming laths.

\subsection{In situ electron backscatter diffraction and comparison with modelling approach}

In some situations, when austenite transforms to bainite, martensite or acicular ferrite, some retained austenite is present after transformation and so it is possible to know the texture of prior austenite. However, in the present welds no retained austenite was detected by EBSD. 
Thus, an in situ observation of texture can provide invaluable information for the validation of transformation models and so here, such experiments on fusion zone material from the LTT weld metal were performed. At the start of the experiment, the EBSD map revealed fully ferritic initial bcc structure. Fiducial markers were used to ensure registry of the areas examined. After heating up to $1000{ }^{\circ} \mathrm{C}$ and holding at this temperature an EBSD map of austenite was collected from same region, indicating large $>30 \mu \mathrm{m}$ austenite grains. After cooling, the final microstructure consisted of ferritic grains size of $\sim 20 \mu \mathrm{m}$.

Figure $5 a$ shows the in situ EBSD map for the initial condition. The highlighted region shown was chosen for analysis in Fig. 5b, and a single orientation within that region extracted for clarity in Fig. $5 c$. For this single grain orientation, the Euler angles were $\left(26.5^{\circ}, 35.3^{\circ}\right.$, $31.2^{\circ}$ ). On heating to $1000{ }^{\circ} \mathrm{C}$, this region transformed to a single $\gamma$ grain, Fig. $6 a$ and $6 b$. For comparison, the austenite orientation inferred ${ }^{20}$ from the $\alpha$ orientation originally present in this region, Fig. $5 b$, is given in Fig. $6 c$; it is readily observed that the $\alpha \rightarrow \gamma$ transformation obeyed the expected orientation relationship.

The measured EBSD map after cooling the material back into the ferritic phase field under no applied load is shown in Fig. $7 a-b$. It is observed that many more grains exist with their $\{001\}$ plane normal along the welding direction (LD) and that also some orientations have disappeared from the selected subregion, particularly those with the $\{001\}$ between the LD and ND. In addition, the grain size obtained on slow cooling without load was larger, and fewer orientations are observed overall. Again, the number of orientations present is less than the 24 possible and so some variant selection has occurred, compare Fig. $7 b$ and $c$. However, included among the orientations found is the orientation originally selected, Figures $7 d$ and $5 c$, which can readily be confirmed to be a permitted variant of the prior austenite grain, Fig. $7 e$. 
Therefore, thermal cycling of the material into the austenite regime and back to ferrite again results in final grain orientations that obey the expected orientation relationships for each transformation. Thus, even where the transformation might traditionally be held to be reconstructive $(\alpha \rightarrow \gamma)$, the orientation relationships are obeyed, presumably because this involves the minimum movement of substitutional atoms. Then on cooling $(\gamma \rightarrow \alpha)$, again the orientation relationships are obeyed, although the original set of orientations are not necessarily recovered, for example the grain with their $\{001\}$ near the welding direction in Fig. $7 b$.

\section{Discussion}

Residual stress analysis in Murakawa et $a l .{ }^{32}$ indicates a difference between the residual stress and distortion patterns in welds manufacture using these two consumables. In both cases the microstructure consisted of acicular ferrite. One might believe that the similarity in microstructures would give rise to similar residual stress patterns. However, the lower temperature at the onset of transformation may result in higher yield strengths, different variant selection conditions and hence textures and internal shear strains, the production of differing amount of thermal strain prior to transformation and also differing transformation strains. ${ }^{25-28}$

Lischewski $^{34}$ reported that the nucleation of the newly formed bcc phase during $\gamma \rightarrow \alpha$ transformation takes place predominantly at triple junctions of the austenite grains. However, the present study did not confirm these observations. The nucleation appeared to occur at austenite grain boundaries. It is notable that there is a difference in grain size after the $\alpha \rightarrow \gamma$ $\rightarrow \alpha$ transformation.

Shirane et $a l .{ }^{40}$ demonstrated that a martensitic ferrite to austenite reverse transformation takes place in B containing 9\% Cr steel. In contrary to this work, the LTT weld consumable 
used in the work present does exhibit a diffusional reverse transformation observed during insitu EBSD experiment.

In refs. ${ }^{39,41}$ is shown that the selection of certain crystallographic variants whose shape deformation relieves the applied stress can be analysed in terms of the overall Gibb's energy of the transformation, composed of its chemical $(\Delta \mathrm{Gc})$ and mechanical $(\Delta \mathrm{Gm})$ contributions. Where the interaction energy $\mathrm{U}$ (Eq. 5) is a significant contributor to $\Delta \mathrm{Gm}$ and is a large fraction of the total $\Delta \mathrm{G}=\Delta \mathrm{Gc}+\Delta \mathrm{Gm}$, then variant selection can occur and contribute to the minimization of $\mathrm{G}$ occurring at equilibrium. This analysis suggests that this condition is satisfied for the LTT wire whereas it is not for the conventional weld metal, presumably because $\Delta \mathrm{Gc}$ is smaller for the LTT wire, which is consistent with it having a lowered transformation temperature. Therefore, in designing a welding consumable that provides variant selection as a means of minimizing residual stress and distortion, $\Delta \mathrm{Gc}$ should be minimised. Such an approach provides a simplified thermodynamic approach to welding consumable design.

\section{Conclusions}

The textures and microstructures observed in GMA welds fabricated using both a conventional ferritic weld filler metal and a low transformation temperature (LTT) wire have been observed. In addition, thermal cycling through the ferrite-austenite-ferrite transformation has been performed suing in situ EBSD on material from the LTT weld fusion zone. The following conclusions can be drawn.

1. In both cases, acicular ferrite microstructures were obtained, and in the case of the conventional weld wire, some allotriomorphic ferrite was also observed.

2. The macroscopic textures observed in the two welds were quite different. 
3. EBSD analysis of the LTT fusion zone showed evidence of variant selection consistent with an applied compressive stress in the welding direction; no such evidence was observed for the conventional welding consumable.

4. Cycling of the LTT fusion zone material through the austenite phase resulted a change in the orientations observed in a small subregion, but these variants all obeyed the expected crystallographic orientation relationships.

It is suggested that the maximisation of the mechanical contribution to the Gibbs energy of transformation and minimisation of the chemical contribution will provide a simple route to the design of welding consumables that exploit variant transformations to minimise residual stress and distortion in GMA welds. Consideration of such transformations would then need to be included in finite element models of the welding process where these are used for joint design and process optimisation.

\section{Acknowledgements}

Authors would like to thank Mrs Tatiana Gorkaya at RWTH Aachen, Germany for performing in situ EBSD maps. This research was supported by a Marie Curie Intra European Fellowship within the $7^{\text {th }}$ European Community Framework and EPSRC.

\section{References}

1. G. E. Totten, M. A. H. Howes and T. Inoue (Eds): 'Handbook of Residual Stress and Deformation of Steel', 2002, ASM International. 
2. K. Masubuchi: 'Analysis of welded structures: residual stresses, distortion, and their consequences', 1980, Oxford, Pergamon Press.

3. J. Eckerlid, T. Nilsson and L. Karlsson: 'Fatigue properties of longitudinal attachments welded using low transformation temperature filler', Sci. Technol. Weld. Join., 2003, 8, (5), 353-359.

4. J. A. Francis, H. J. Stone, S. Kundu, H. K. D. H. Bhadeshia, R. B. Rogge, P. J. Withers and L. Karlsson: 'The effects of filler metal transformation temperature on residual stresses in a high strength steel weld', J. Press. Vessel Technol.-Trans. ASME”, 2009, 131, (4), 041401-041409.

5. A. Ohta, K. Matsuoka, N.T. Nguyen, Y. Maeda and N. Suzuki: 'Fatigue strength improvement of lap joints of thin steel plate using low-transformation-temperature welding wire', Am. Weld. J., 2003, 82, (4), 78-83.

6. A. Ohta, N. Suzuki, Y. Maeda, K. Hiraoka and T. Nakamura: 'Superior fatigue crack growth properties in newly developed weld metal', Int. J. Fatigue, 1999, 21, S113S118.

7. A. Ohta, O. Watanabe, K. Matsuoka, C. Shiga, S. Nishijima, Y. Maeda, N. Suzuki, and T. Kubo: 'Fatigue strength improvement by using newly developed low transformation temperature welding material', Weld World, 1999, 43, (6), 38-42.

8. A. A. Shirzadi, H. K. D. H. Bhadeshia, L. Karlsson and P. J. Withers: 'Stainless steel weld metal designed to mitigate residual stresses', Sci. Technol. Weld. Join., 2009, 14, (6), 559-565.

9. S. Zenitani, N. Hayakawa, J. Yamamoto, K. Hiraoka, Y. Morikage, T. Kubo, K. Yasuda and K. Amano: 'Development of new low transformation temperature welding consumable to prevent cold cracking in high strength steel welds', Sci. Technol. Weld. Join., 2007, 12, (6), 516-522. 
10. H. K. D. H. Bhadeshia: 'Possible effects of stress on steel weld microstructures', 'Mathematical Modelling of Weld Phenomena', $2^{\text {nd }}$ edn, 1995, United Kingdom, Institute of Materials.

11. J. A. Francis, H. J. Stone, S. Kundu, R. B. Rogge, H. K. D. H. Bhadeshia, P. J. Withers and L. Karlsson: 'Transformation temperatures and welding residual stresses in ferritic steels', Proc. ASME Pressure Vessels and Piping Division Conference, San Antonio, Texas, USA, July 2007, American Society of Mechanical Engineers, 949956.

12. Y. Mikami, Y. Morikage, M. Mochizuki and M. Toyoda: 'Angular distortion of fillet welded $\mathrm{T}$ joint using low transformation temperature welding wire', Sci. Technol. Weld. Join., 2009, 14, (2), 97-105.

13. J. Romero, M. Preuss and J. Quinta da Fonseca: 'Texture memory and variant selection during phase transformation of a zirconium alloy', Acta Mater., 2009, 57, (18), 5501-5511.

14. H. R. Wenk, I. Lonardelli and D. Williams: 'Texture changes in the hcp RT bcc RT hcp transformation of zirconium studied in situ by neutron diffraction', Acta Mater., 2004, 52, (7), 1899-1907.

15. M. Karadge, M. Preuss, C. Lovell, P. J. Withers and S. Bray: 'Texture development in Ti-6Al-4V linear friction welds', Mater. Sci. Eng.: A., 2007, A459, (1-2), 182-191.

16. N. Yoshinaga, H. Inoue, K. Kawasaki, L. Kestens and B. C. De Cooman: 'Factors Affecting Texture Memory Appearing through alpha - > gamma - > alpha Transformation in IF Steels', Mater. Trans., 2007, 48, (8), 2036-2042.

17. J. S. Bowles and J. K. Mackenzie: 'The crystallography of martensite transformations I', Acta Metall., 1954, 2, (1), 129-137. 
18. J. K. Mackenzie and J. S. Bowles: 'The crystallography of martensite transformations II', Acta Metall., 1954, 2, (1), 138-147.

19. M. S. Wechsler, D. S. Lieberman and T. A. Read: 'On the theory of the formation of martensite', Trans. AIME J. Metals, 1953, 197, 1503-1515.

20. Kundu, S., 'Transformation strain and crystallographic texture in steels', $\mathrm{PhD}$ thesis, University of Cambridge, Cambridge, UK, 2007.

21. S. Kundu and H. K. D. H. Bhadeshia: 'Transformation texture in deformed stainless steel', Scrip. Mater., 2006, 55, (9), 779-781.

22. H. K. D. H. Bhadeshia, H.F.G. Abreu and S. Kundu: 'Calculation of crystallographic Texture due to Displacive Transformations', Int. J. Mater. Res., 2008, 99, (4), 342346.

23. S. Kundu and H. K. D. H. Bhadeshia: 'Crystallographic texture and intervening transformation', Scrip. Mater., 2007, 57, (9), 869-872.

24. S. S. Babu and H. K. D. H. Bhadeshia: 'Stress and the acicular ferrite transformation', Mater. Sci. Eng.: A., 1992, A156, (1), 1-9.

25. J. C. Bokros and E. R. Parker: 'The mechanism of the martensite burst transformation in Fe-Ni single crystals’, Acta Metall., 1963, 11, (12), 1291-1301.

26. S. Chatterjee, H. S. Wang, J. R. Yang and H. K. D. H. Bhadeshia: 'Mechanical stabilisation of austenite', Mater. Sci. Technol., 2006, 22, (6), 641-644.

27. T. N. Durlu and J. W. Christian: 'Effect of prior deformation on the martensite burst transformation in single crystals of an Fe-Ni-C alloy', Acta Metall., 1979, 27, (4), 663666.

28. K. Hase, C. Garcia-Mateo and H. K. D. H. Bhadeshia: 'Bainite formation influenced by large stress', Mater. Sci. Technol., 2004, 20, (12), 1499-1505. 
29. C. M. Davies, M. Béreš, D. Hughes, D. Dye and K. M. Nikbin: 'The Influence of Geometric and Welding Parameters on Residual Stress in Thin Welded Steel Structures', Proc. ASME Pressure Vessels and Piping Division Conference, Prague, Czech Republic, July, 2009.

30. C. M. Davies, R. C. Wimpory, M. Béreš, M. P. Lightfoot, D. Dye, E. Oliver, N. P. O'Dowd, G. J. Bruce and K. M. Nikbin: 'The effect of residual stress and microstructure on distortion in thin welded steel plates', Proc. ASME Pressure Vessels and Piping Division Conference, San Antonio, Texas, USA, July 2007, American Society of Mechanical Engineers.

31. C. M. Davies, R. C. Wimpory, D. Dye and Nikbin: 'The effect of plate dimensions on residual stresses in welded thin steel plates', Proceedings of the ASME Pressure Vessels and Piping Conference, New York, NY, v. 6, 309-319, 2009.

32. H. Murakawa, M. Béreš, C. M. Davies, S. Rashed, A. Vega, M. Tsunori, K. M. Nikbin and D. Dye: 'The Effect of Low Transformation Temperature Weld Filler Metal on Welding Residual Stress', Sci. Technol. Weld. Join., 2010, 15, 393-399.

33. K. Ishida: 'Calculation of the effect of alloying elements on the Ms temperature in steels', J. Alloys and Comp., 1995, 220, (1), 126-131.

34. I. Lischewski, D. M. Kirch, A. Ziemons and G. Gottstein: 'Investigation of the $\alpha-\gamma-\alpha$ Phase Transformation in Steel: High-Temperature In situ EBSD Measurements', Texture, Stress, and Microstructure, 2008. DOI:10.1155/2008/294508.

35. H. J. Bunge, M. Humbert and P. I. Welch: 'Texture transformation with variant selection', Scrip. Metall., 1983, 17, (12), 1403-1405.

36. H. K. D. H. Bhadeshia, H.F.G. Abreu and S. Kundu: 'Crystallographic Texture due to Displacive Transformations', Int. J. Mater. Res., 2008, 99, (4), 342-346. 
37. A. A. Shirzadi, H.F.G. Abreu, L. Pocock, D. Klobčar, P. J. Withers and H. K. D. H. Bhadeshia: 'Bainite Orientation in Plastically Deformed Austenite', Int. J. Mater. Res., 2009, 100, 40-45.

38. H. K. D. H. Bhadeshia: 'Bainite in steels: transformations, microstructure and properties', $2^{\text {nd }}$ edn, Vol. 1, 2001, London, IOM Communications.

39. S. Kundu, K. Hase and H. K. D. H. Bhadeshia: 'Crystallographic texture of stressaffected bainite', Proc. Royal Society A: Mathematical, Physical and Engineering Science, 2007, v. 463, n. 2085, p. 2309-2328.

40. T. Shirane, S. Tsukamoto, Y. Adachi, T. Hanamura, M. Shimizu, F. Abe: 'Ferrite to austenite reverse transformation process in $\mathrm{B}$ containing $9 \% \mathrm{Cr}$ heat resistant steel HAZ', Sci. Technol. Weld. Join., 2009, 14, (8), 698-707.

41. H. K. D. H. Bhadeshia, S. A. David, J. M. Vitek and R. W. Reed: 'Stress induced transformation to bainite in FeCrMoC pressure vessel steel', Mater. Sci. Technol., 1991, 7, (8), 686-698. 


\section{Tables}

Table 1 Chemical composition (wt. \%) of steel plate, conventional weld wire and LTT weld wire [32].

\begin{tabular}{llllllllll}
\hline & $\mathrm{C}$ & $\mathrm{Si}$ & $\mathrm{Mn}$ & $\mathrm{P}$ & $\mathrm{S}$ & $\mathrm{Cu}$ & $\mathrm{Ni}$ & $\mathrm{Cr}$ & $\mathrm{Nb}$ \\
\hline Steel plate & 0.11 & 0.18 & 1.29 & 0.01 & 0.004 & 0.02 & 0.03 & 0.03 & 0.01 \\
CW & 0.07 & 0.61 & 1.42 & 0.01 & 0.010 & 0.14 & 0.04 & 0.02 & 0.02 \\
LTTW & 0.04 & 0.32 & 0.36 & 0.008 & 0.004 & 0.15 & 11.9 & - & - \\
\hline
\end{tabular}

Table 2 Welding parameters

\begin{tabular}{lllllll}
\hline & Weld & Weld & Weld & Weld & Heat & Parameter \\
& length & Speed & Current & voltage & input & Q/h \\
& {$[\mathrm{mm}]$} & {$\left[\mathrm{mm} \mathrm{s}^{-1}\right]$} & {$[\mathrm{A}]$} & {$[\mathrm{V}]$} & {$\left[\mathrm{kJ} \mathrm{mm}^{-1}\right]$} & {$\left[\mathrm{J} \mathrm{mm}^{-3}\right]$} \\
\hline CW & 500 & 2.7 & 150 & 18 & 1.00 & 62.5 \\
LTTW & 500 & 3.5 & 180 & 20 & 1.03 & 64.3 \\
\hline
\end{tabular}




\section{Figures}

Figure 1 Macrograph fusion zone and heat affected zone of conventional weld wire.

Figure 2 SEM-SE (left) and TEM-BF (right) micrographs of $a$ and $b$ conventional weld wire; $c$ and $d$ LTT weld wire.

Figure 3 Measured macroscopic texture of the fusion zones from welds manufacture using $a$ the conventional weld wire and $b$ the LTT weld wire.

Figure 4 EBSD inverse pole figure (IPF) map with selected subset of $a$ conventional weld wire and $b$ LTT weld wire, $c$ comparison of experimentally determined $\{100\}$ pole figures in highlighted subregion of $a$ with computed $\{100\}$ pole figures following $\alpha \rightarrow \gamma \rightarrow \alpha$ transformation, $d$ the same comparison as in $c$ but considering subregion of $b$. Exp denotes experimental, Calc calculated and $13 \mathrm{~V}$ number of variants considered in the computation.

Figure 5 In situ EBSD map for the initial, ferritic condition $a$, measured orientations for the highlighted subregion $b$, and for a single orientation within the subregion $c$.

Figure 6 In situ EBSD map for the same region as Figure 5, after heating to $1000{ }^{\circ} \mathrm{C}$ and transformation to austenite, $a$. Also shown, $b$ is the measured austenite orientation for the subregion highlighted, which is the same region as in Figure $7 a$ and $c$ calculated Pole Figure from one grain within the highlighted region in Figure $5 a$ following $\alpha \rightarrow \gamma$ transformation. 
Figure 7 In situ EBSD map, $a$, after cooling back to the ferritic phase field at $70{ }^{\circ} \mathrm{C}$, and $b$ measured bcc orientations in the highlighted subregion, which is the same region as in Figures 5 and 6. In $c$, the calculated possible bcc orientations are shown for all 24 variants formed from the initial fcc orientation shown in Figure $6 b$ and $a$. These include the orientation shown in $e$, which is one of the orientations observed in the highlighted subregion, $d$ after $\alpha \rightarrow \gamma \rightarrow \alpha$ transformation. 


\section{Science and Technology of Welding and Joining ('the Journal')}

\section{ASSIGNMENT OF COPYRIGHT}

In order for W.S Maney \& Son Ltd, trading as Maney Publishing ('the Publisher'), to ensure the widest possible dissemination and protection of articles published in the Journal, we request authors to assign worldwide copyright in print, digital and other media in their article, including abstracts, to Institute of Materials, Minerals and Mining. This enables the Publisher to ensure maximum international copyright protection against infringement, and to disseminate your article, and the Journal, to the widest possible worldwide readership. Should the article be rejected from the Journal for any reason, all rights assigned within this document revert back to the author(s) of the article.

Please read the explanatory notes of this agreement on the following page.

1. In consideration of the undertaking set out in paragraph 2, the author(s) as beneficial owner(s) hereby assign(s) to Institute of Materials, Minerals and Mining all rights, title and interest in the copyright throughout the world in the article named below (which shall be taken to include any or all supplementary material associated with the article ${ }^{*}$ ) for the full legal term of copyright.

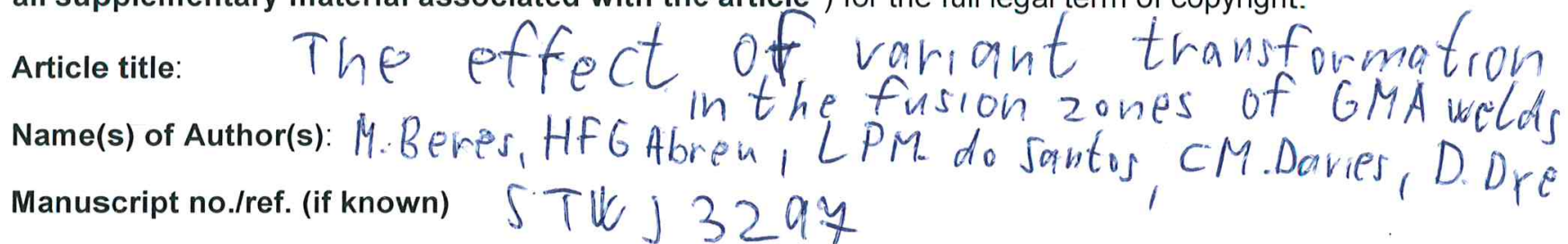

If this paper is sponsored for Open Access by your grant funders, please follow the MORE OpenChoice route by signing and returning this copyright assignment to the address below, and find details of the policy and how to make payment at www.maneyonline.com/openaccess.

So that there should be no doubt, it is understood and agreed that this assignment includes the right to publish or adapt (subject to paragraphs 3 and 4) the material in the article for use in conjunction with computer systems, including networks. The article may be published in printed, CD-ROM, microfiche, online, or other machine-readable form, or in any other format or medium (electronic or otherwise) approved by Institute of Materials, Minerals and Mining; and subject to data mining.

2. Maney Publishing, as the Journal's publisher, hereby undertakes to prepare for publication and publish in the Journal, the Article named in paragraph 1.

3. The editor of the Journal, and the Publisher, are empowered to make such editorial changes as may be necessary to make the Article suitable for publication. Every effort will be made to consult the Author(s) if substantive changes are required.

4. The author(s) hereby assert(s) their moral rights under the terms of the Copyright Designs and Patents Act 1988 to be identified as the Author(s) of the Article.

5. The author(s) warrant(s) that the article is the author(s)' original work, has not been published before, either in part or whole, and is not currently under consideration for publication elsewhere. The author(s) also warrant(s) that (a) the article contains no libellous or unlawful statements, (b) it in no way infringes the rights of others (including the holders of copyright in material used within the article), (c) that permission has been obtained to reproduce any material or illustrations for which they do not hold copyright, and that (d) the author(s), as the owners of the copyright, is (are) entitled to make the assignment set out in this agreement. The author(s) hereby indemnifies/indemnify the Publisher against any claims for breach of the warranties given above. 
6. In cases where the article is a translation of a previously published article, the author(s) warrant(s) that full permission has been obtained to carry out and publish the translation of the article from its original language, and that it in no way infringes the rights of others (including the holders of copyright in material used within the original Article).

7. The author(s) warrant(s) that the article contains no plagiarised material and agree(s) that the article may be checked for plagiarism and other ethical questions (including checks using automated software packages). The Publisher reserves the right to withdraw or retract any article for which, in its reasonable opinion, valid concerns exist over the originality of the article, or its compliance with the Journal's ethical policy. Maney's plagiarism and ethical policy may be read in full at www.maneyonline.com/page/authors/publishingethics-general.

*If the author(s) cannot assign copyright for any or all the supplementary material, the clause in parentheses should be struck out and a licence to publish provided for this material. If copyright is held by a third party, permission to reproduce this material must be obtained from the copyright holder as laid out in paragraph 5 of this form and submitted to the publisher.

\section{Copyright Assignment}

I confirm that all the co-authors, named above in 1, know that the article has been submitted to the Journal.

I hereby sign this Assignment of Copyright with the full knowledge and agreement of all authors.

Signed:

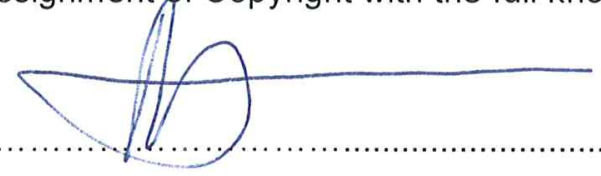

Printed name:

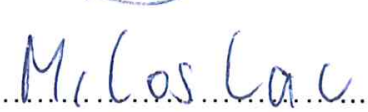
Date: $5 / 2 / 2075$

\section{Please note: it is essential for publication that Maney Publishing receive this signed Assignment of} Copyright form. Without it, we will be unable to proceed to publication.

Please complete all specified fields and return this signed form to the Production Editor of the Journal.

Production Editor, STW, for Maney Publishing

stw@maneypublishing.com; fax: +44 (0) 2074517307

1 Carlton House Terrace, London SW1Y 5AF, UK 
Non-colour figure

Click here to download high resolution image

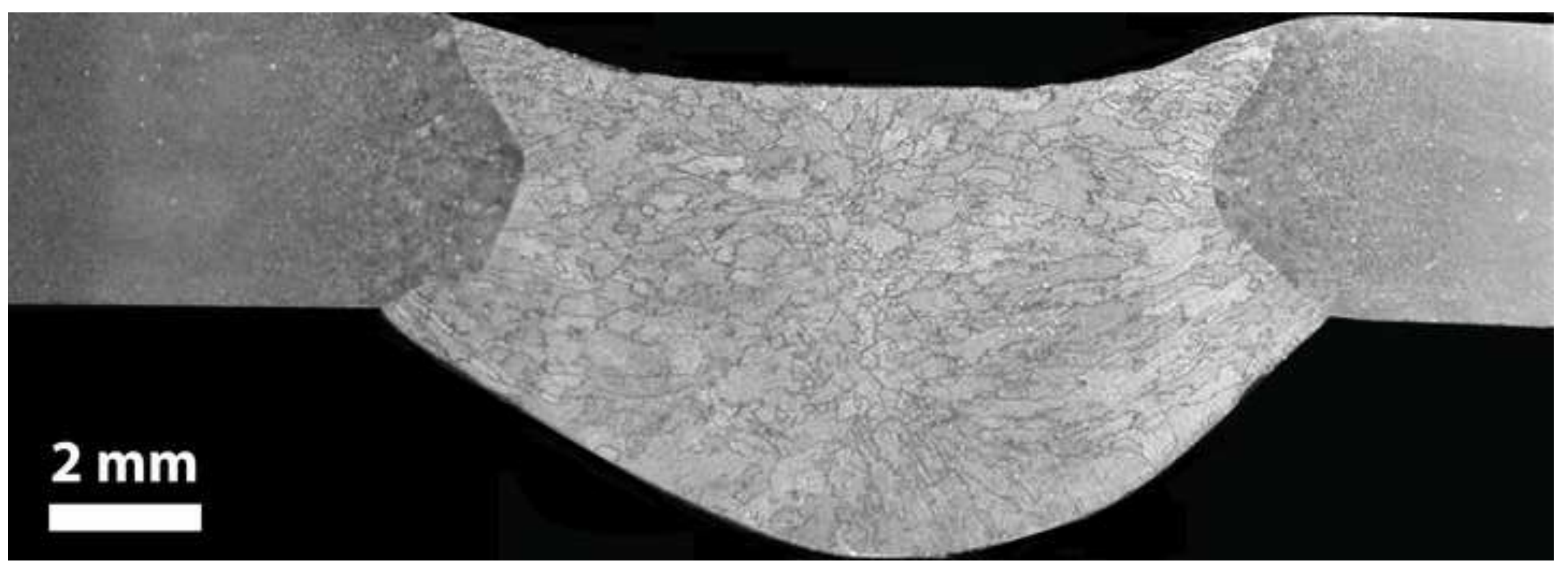




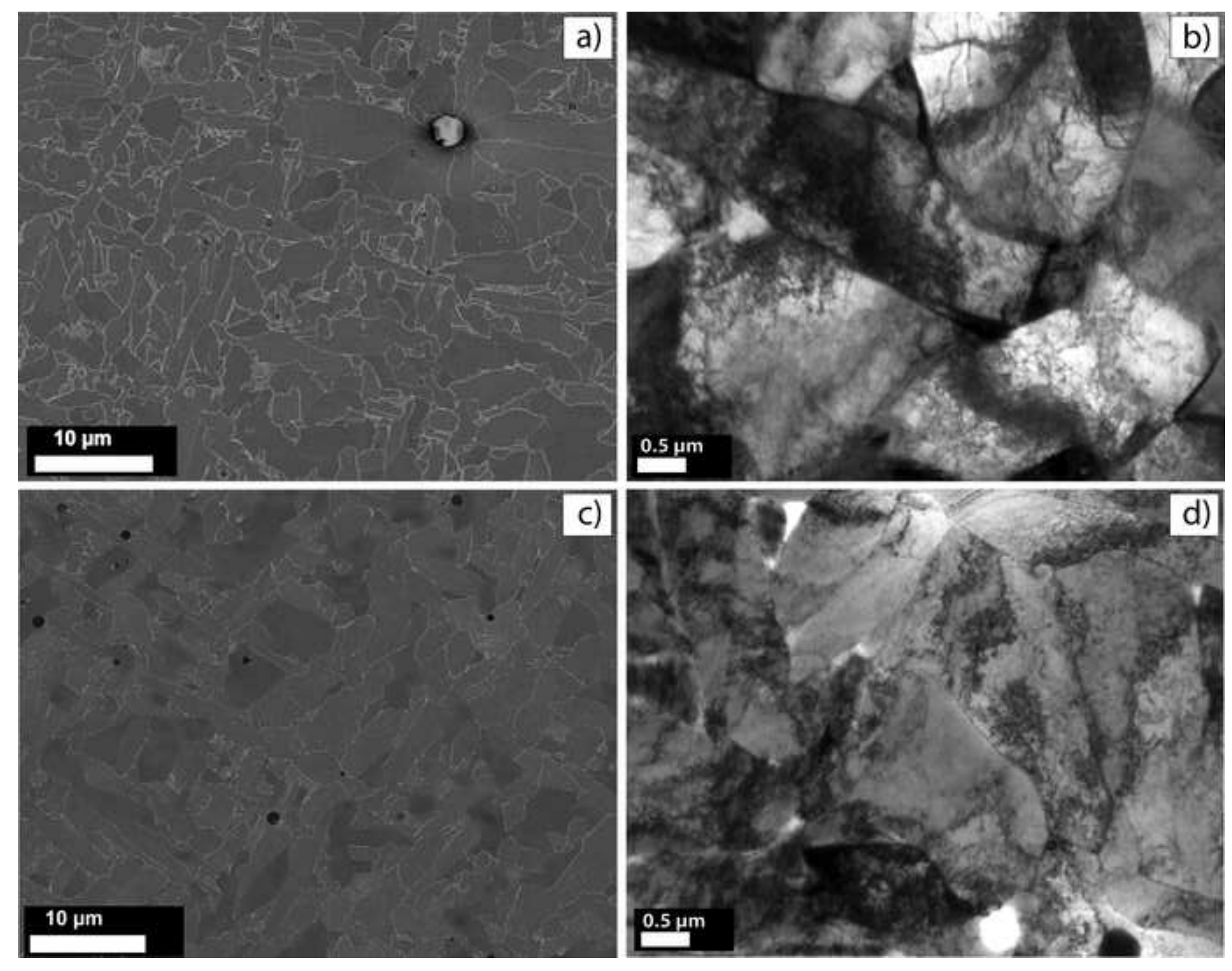
e

(
. 

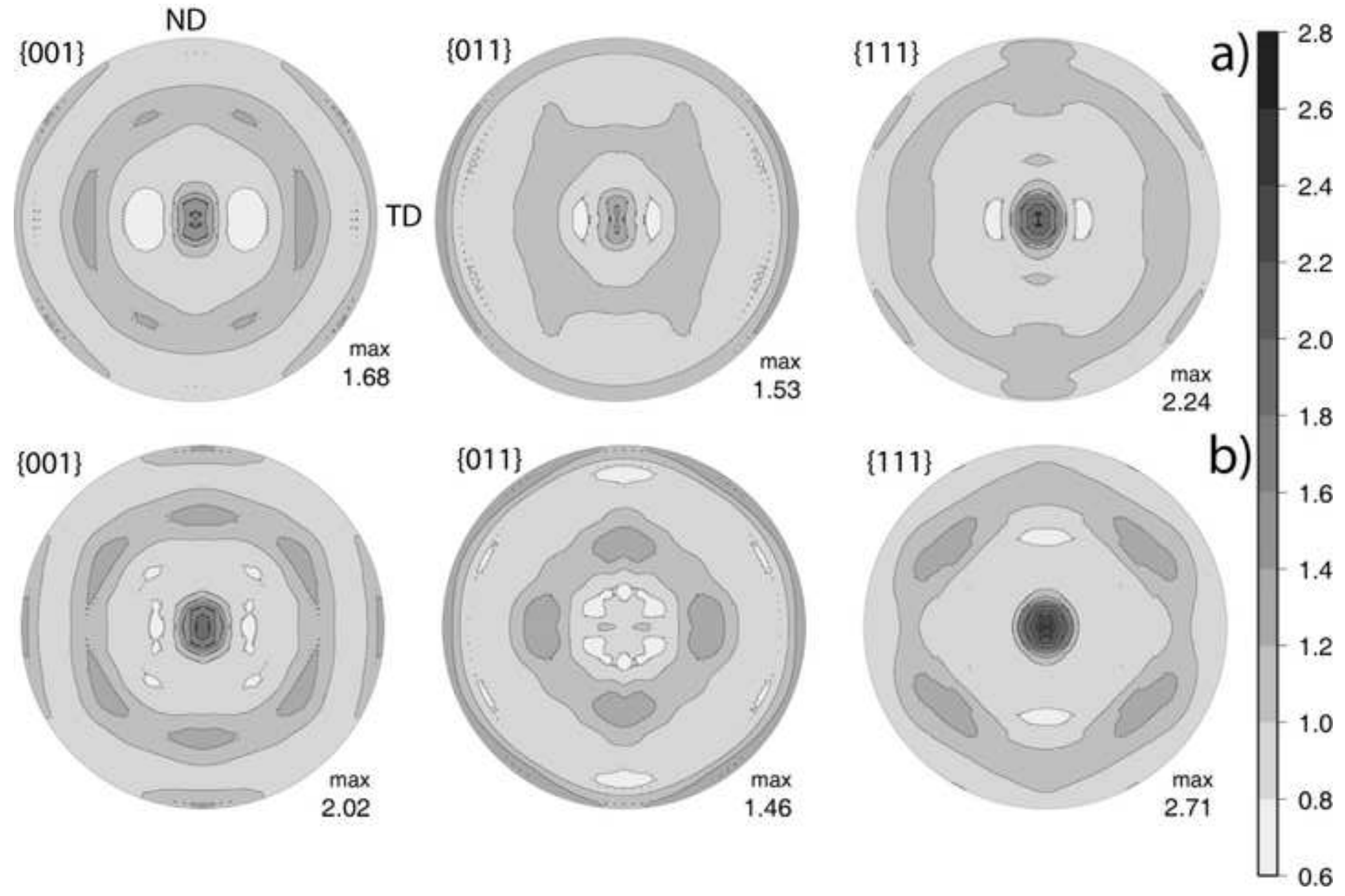
Colour figure

Click here to download high resolution image
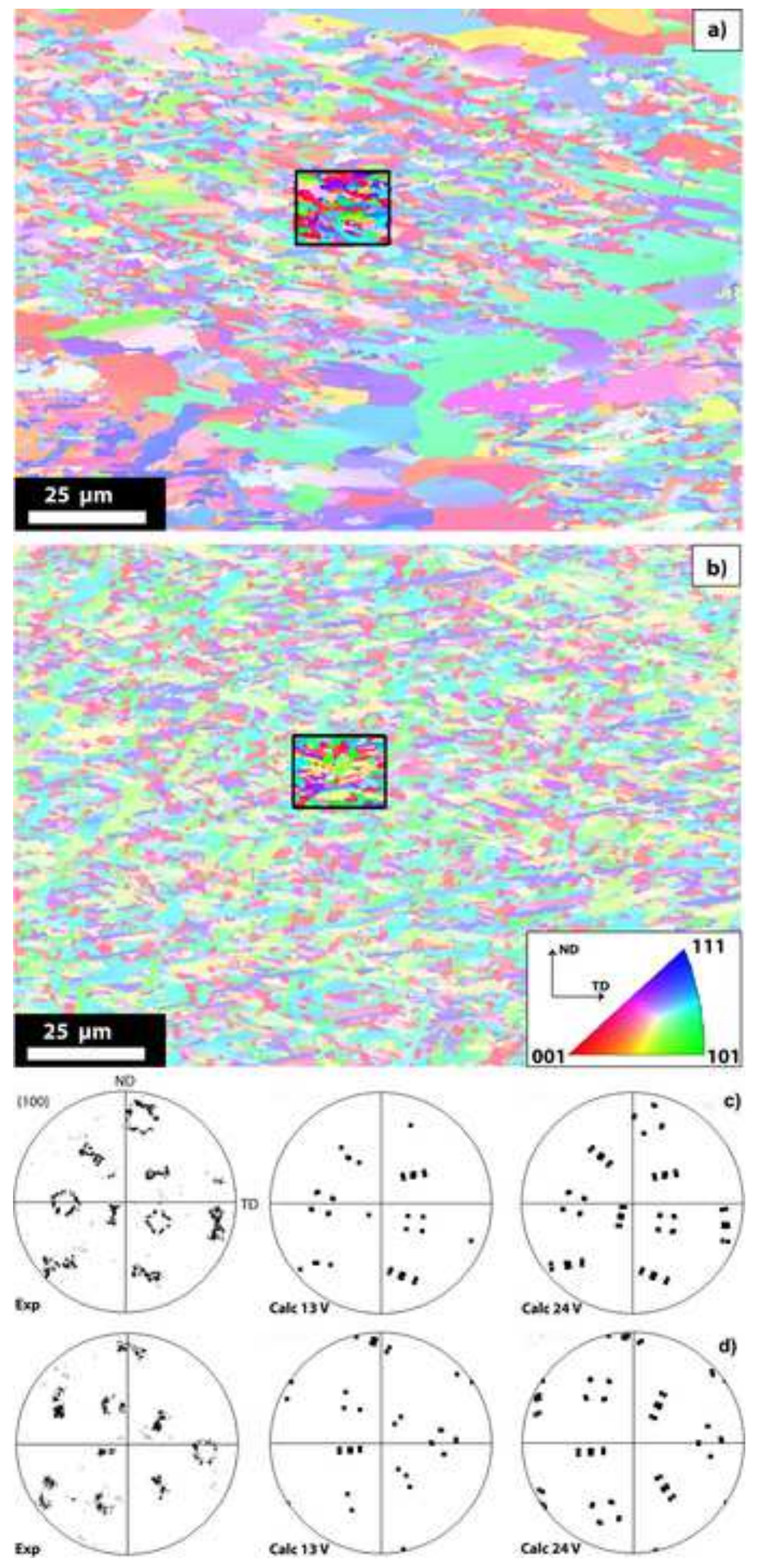

$\exp$

Calk 13V

Calc 24V

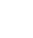

. 

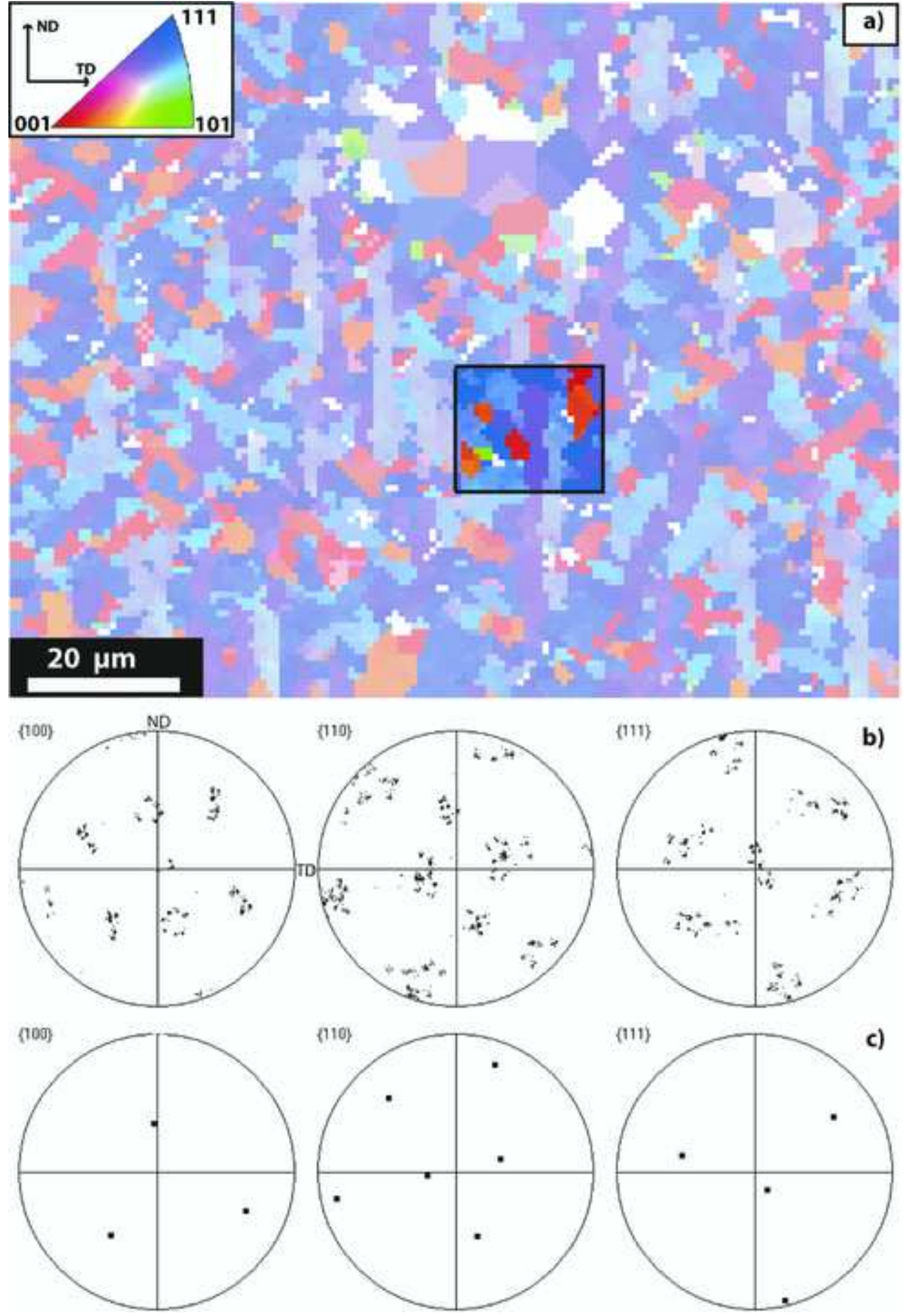

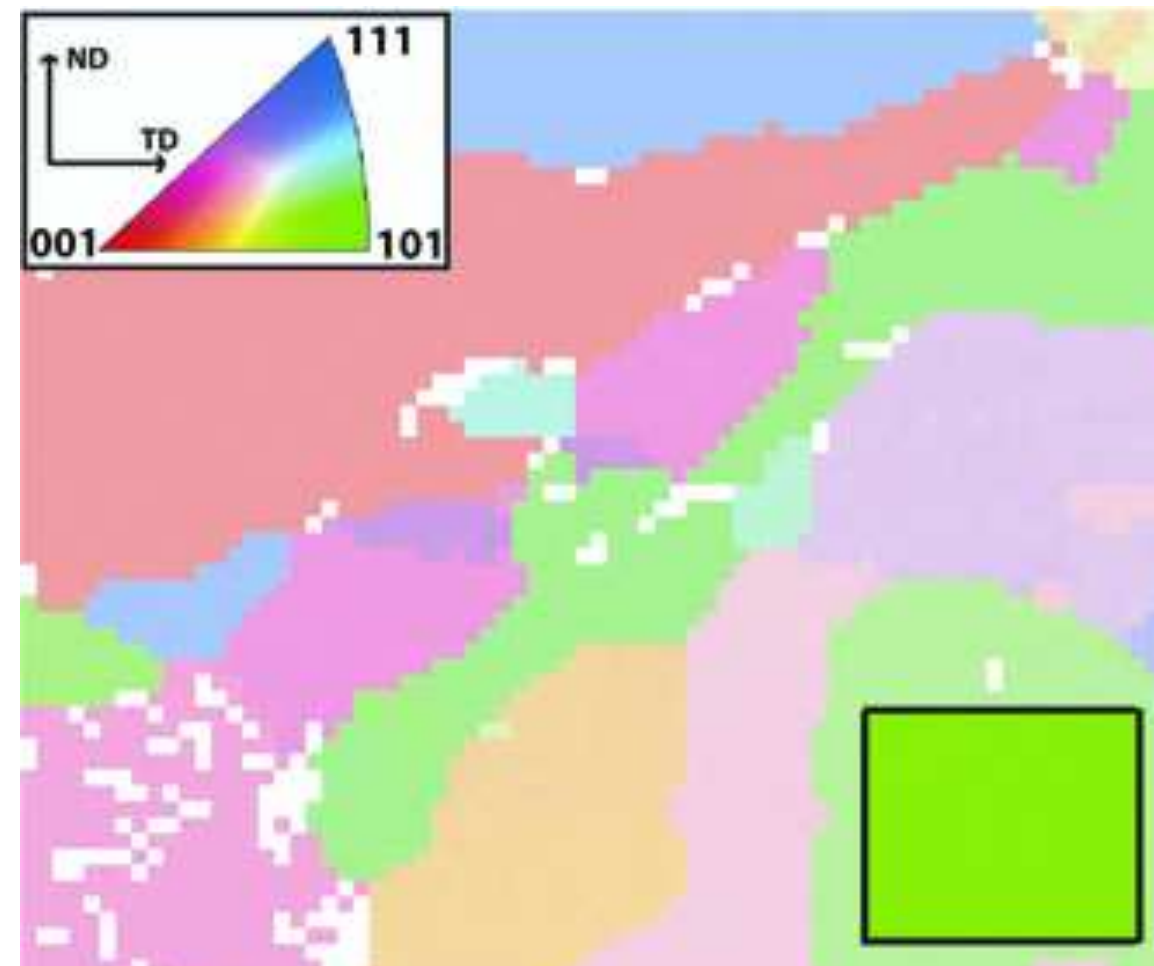

\section{$20 \mu \mathrm{m}$}
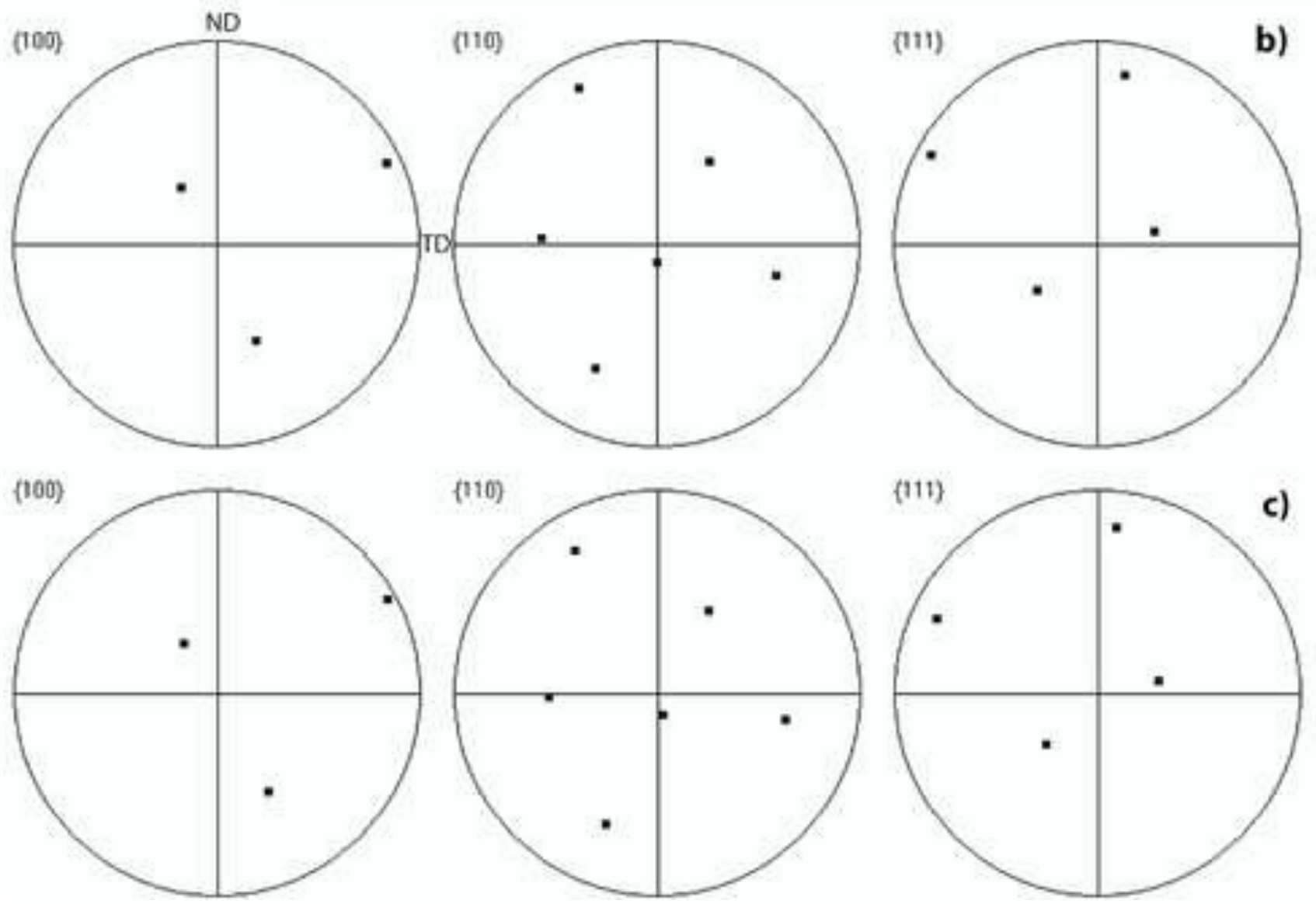

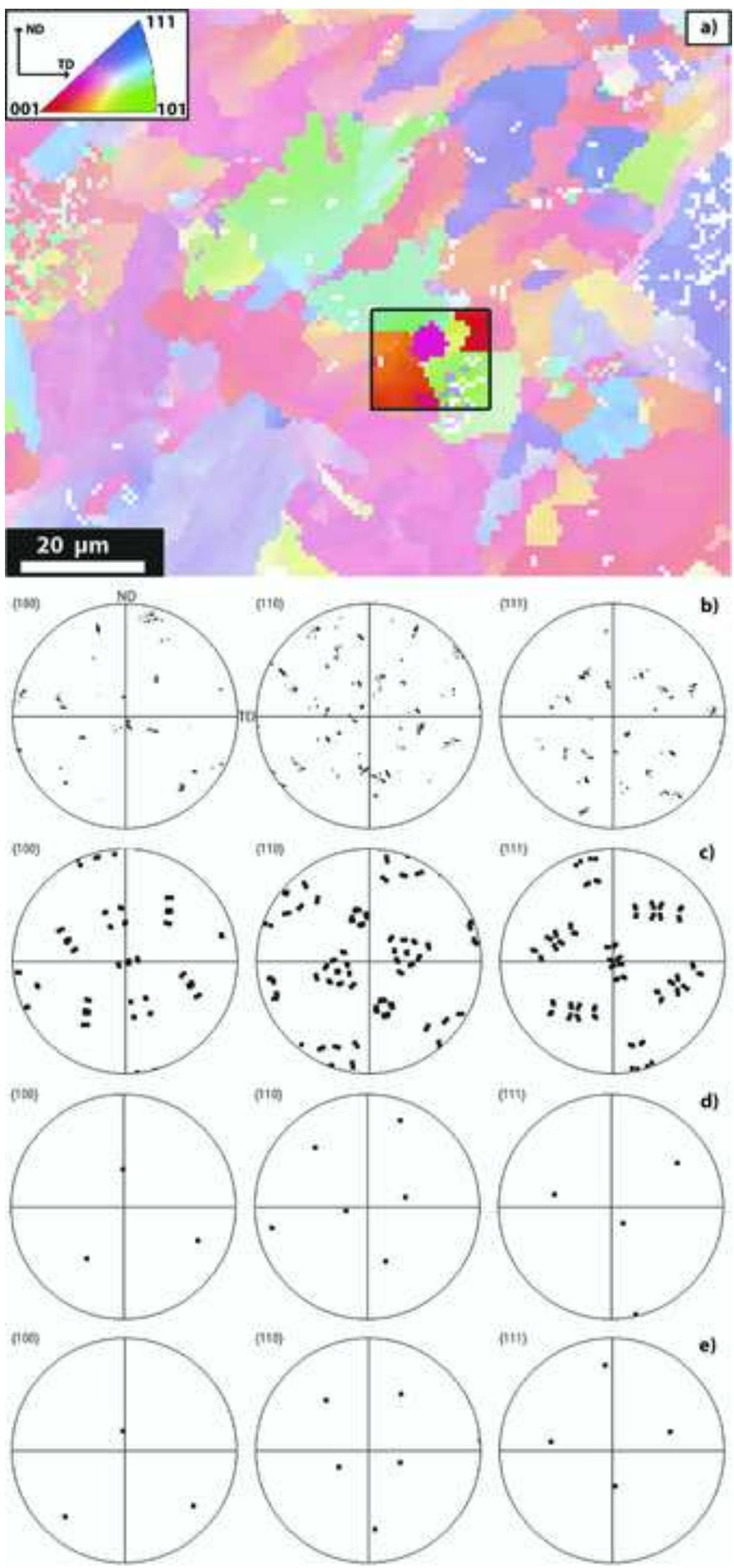